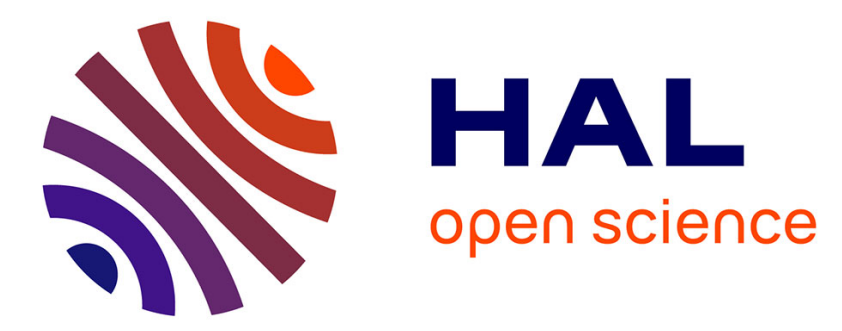

\title{
Unusual mixed solvent supramolecular crystal framework formed of a new tecton-like tetracarboxylic building block $\uparrow$
}

\author{
Edwin Weber, Ines Hauptvogel, Wilhelm Seichter
}

\section{- To cite this version:}

Edwin Weber, Ines Hauptvogel, Wilhelm Seichter. Unusual mixed solvent supramolecular crystal framework formed of a new tecton-like tetracarboxylic building block $\dagger$. Supramolecular Chemistry, 2011, 23 (05), pp.398-406. 10.1080/10610278.2010.527979 . hal-00701862

\section{HAL Id: hal-00701862 \\ https://hal.science/hal-00701862}

Submitted on 27 May 2012

HAL is a multi-disciplinary open access archive for the deposit and dissemination of scientific research documents, whether they are published or not. The documents may come from teaching and research institutions in France or abroad, or from public or private research centers.
L'archive ouverte pluridisciplinaire HAL, est destinée au dépôt et à la diffusion de documents scientifiques de niveau recherche, publiés ou non, émanant des établissements d'enseignement et de recherche français ou étrangers, des laboratoires publics ou privés. 


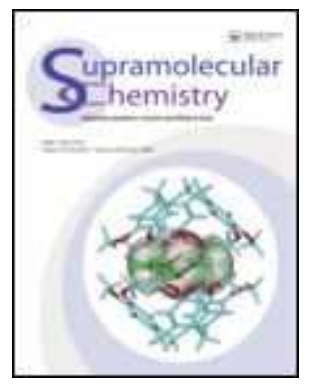

\section{Unusual mixed solvent supramolecular crystal framework formed of a new tecton-like tetracarboxylic building block +}

\begin{tabular}{|r|l|}
\hline Journal: & Supramolecular Chemistry \\
\hline Manuscript ID: & GSCH-2010-0169.R1 \\
\hline Manuscript Type: & Full Paper \\
\hline $\begin{array}{r}\text { Author: } \\
\text { Complete List of Authors: }\end{array}$ & $\begin{array}{l}\text { Weber, Edwin; TU Bergakademie Freiberg, Organische Chemie } \\
\text { Hauptvogel, Ines; TU Dresden, Department of Chemisty } \\
\text { Seichter, Wilhelm; TU Bergakademie Freiberg, Institut für } \\
\text { Organische Chemie }\end{array}$ \\
\hline Keywords: & $\begin{array}{l}\text { tetracarboxylic acid, dimethyl sulfoxide, chloroform, crystalline } \\
\text { complex, x-ray crystal structure }\end{array}$ \\
\hline \\
\hline $\begin{array}{l}\text { Note: The following files were submitted by the author for peer review, but cannot be converted } \\
\text { to PDF. You must view these files (e.g. movies) online. }\end{array}$ \\
\hline $\begin{array}{l}\text { 3 CIF report.eml } \\
\text { 3fin.cif }\end{array}$ \\
\hline
\end{tabular}

\section{SCHOLARONE Manuscripts}


Graphical Abstract

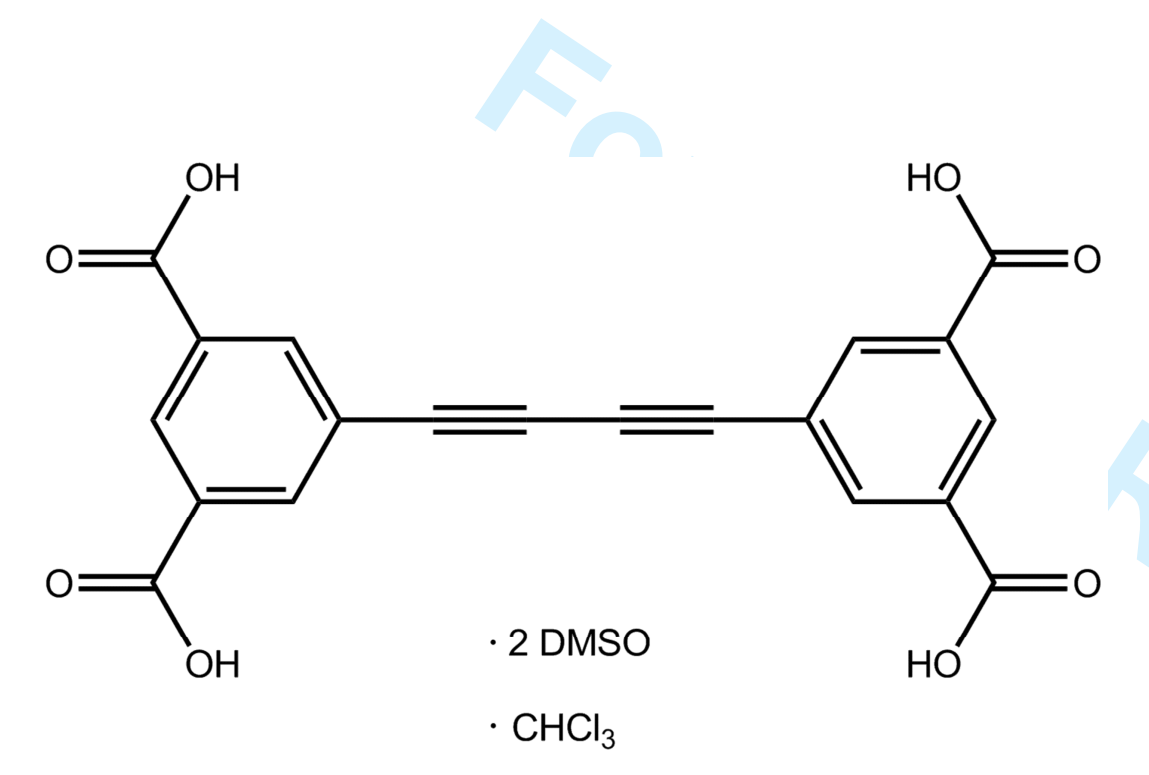

Ines M. Hauptvogel, Wilhelm Seichter and Edwin Weber*

Unusual mixed solvent supramolecular crystal framework formed of a new tecton-like tetracarboxylic building block

Synthesis of a new geometrically defined tetracarboxylic acid molecule is described and the crystalline framework structure of its mixed solvent complex with DMSO and chloroform is discussed. 


\section{Unusual mixed solvent supramolecular crystal framework formed of a new tecton-like tetracarboxylic building block $\dagger$}

Ines M. Hauptvogel, \$ Wilhelm Seichter, and Edwin Weber*

Institut für Organische Chemie, Technische Universität Bergakademie Freiberg, Leipziger Str. 29, D-09596 Freiberg/Sachs., Germany

+ Dedicated to the late Prof. Yurii A. Simonov, Institute of Applied Physics, Academy of Sciences of Moldova, Kishinev, Moldova

₹ Present address: Institut für Anorganische Chemie der TU Dresden, Helmholtzstr. 10, D-01069 Dresden, Germany

* Corresponding author. Email: Edwin.weber@chemie.tu-freiberg.de 


\begin{abstract}
A new tecton-like tetracarboxylic compound $\mathbf{1}$ featuring two isophthalic acid groups attached to both ends of a rigid 1,3-butadiyne spacer unit is synthesized using acetylene blocking/deblocking and coupling techniques. Crystallization of $\mathbf{1}$ from DMSO-chloroform solution gives rise to the formation of an unusual mixed solvent crystalline framework structure 1a containing DMSO and chloroform as secondary and tertiary components in 1:2:1 stoichiometric ratio. The X-ray crystal structure of 1a shows interesting stacking mode and hydrogen-bonded, three-dimensional network architecture with the two solvent species being involved in different behaviour pattern.
\end{abstract}

Keywords: tetracarboxylic acid; dimethyl sulfoxide; chloroform; crystalline complex; x-ray crystal structure

\title{
Introduction
}

Carboxylic acids featuring a well defined shape have developed to a key position in the controlled assembly of supramolecular systems with a variety of uses in different branches of crystal engineering (1-3). This covers the carboxylic acids as hosts for crystalline inclusion formation (4) as well as their functional behaviour of a tecton (5), allowing the targeted formation of two- and three-dimensional hydrogen bond stabilized network structures $(6,7)$, although the carboxylic building blocks are brought different into action in these particular fields. While in the object of crystalline host-guest complexation the carboxylic groups are primarily intended for hydrogen bonding to the molecular guest species (8), they are used in the network construction for cyclic hydrogen-bonded pair formation (6,7,9-11). Moreover, rigid oligocarboxylic acid molecules are also very efficiently employed as coordinative linkers in the formation of open organic-inorganic hybrid frameworks (MOFs) $(12,13)$. This implies that for hydrogen-bonded guest inclusion the carboxylic groups are endo in the attachment to the host molecule but at peripheral site in the tectones and linkers. With reference to the tectons, tetracarboxylic acids composed of two isophthalic acid groups connected at both ends of a linear spacer moiety, varying in the length, have been studied in their preference towards the formation of close packed, open parallel or Kagomé networks $(11,14)$. In the case of biphenyl-3,3',5,5'- 
tetracarboxylic acid (two directly connected isophthalic acid groups), open parallel network formation is observed in the solid state structure, whereas the use of a very elongated 1,4phenylene-bis(ethynylene) spacer unit between the isophthalic acid moieties produces a Kagomé assembly of the respective molecules adsorbed on highly oriented pyrolytic graphite, and the intermediate compound with a short ethynylene spacer results in the formation of a mixed pattern containing small areas of the two different motifs (14). Thus the length of the spacer unit in the tetracarboxylic molecules is shown to exert a distinct influence on the network structure to be formed.

Referring to the present compound 1 (Scheme 1), we describe the synthesis of a new member of this particular substance class of bisisophthalic acids featuring with the 1,3butadiyne-1,4-diyl spacer unit a molecule of medium length. Crystallization of $\mathbf{1}$ from a solvent mixture of DMSO and chloroform yielded an interesting stacking mode and hydrogen-bonded, three-dimensional mixed solvent containing network architecture of 1a with the two solvent species being involved in different behaviour pattern, the structure of which is reported and discussed under the specific circumstances.

\section{Results and discussion}

\section{Synthesis}

Synthesis of the title compound $\mathbf{1}$ was performed as specified in Scheme 2. This involves reaction of the starting compound dimethyl 5-iodoisophthalate (2) (15) with MEBYNOL using a Pd-catalyzed Songashira coupling procedure $(16,17)$ to give the blocked acetylenic diester $\mathbf{3}$. The 5-ethynylisophthalic acid (4) was prepared from 3 via removal of the blocking group with $\mathrm{KOH}$ in $n-\mathrm{BuOH}$, yielding as an intermediate the dipotassium salt of $\mathbf{4}$, which was converted into $\mathbf{4}$ by the reaction with hydrochloric acid. Sulphuric acid catalyzed esterification of $\mathbf{4}$ with methanol gave the corresponding diester $\mathbf{5}$. Alternatively, the diester $\mathbf{5}$ could also be obtained in a selective single-step deblocking reaction from 3 using sodium hydride in toluene (18). Actually, the compound $\mathbf{5}$ has already been described in the literature applying a similar synthetic route $(19,20)$ but being based on the rather costly TMS-acetylene instead of the cheaper MEBYNOL as the blocking reagent. The diester 5 was subjected to an Eglinton coupling reaction $(21,22)$ with copper(II) acetate in pyridine-methanol to produce the tetraester 6. This ester was 


\section{$X$-ray structural study}

Crystallization of the tetracarboxylic acid $\mathbf{1}$ from a solvent mixture of dimethylsulfoxide and chloroform yields a ternary complex 1a containing 1, DMSO and chloroform in the stoichiometric ratio 1:2:1. Crystallographic data and selected refinement parameters of the structure are summarized in Table 1. Information regarding possible non-covalent interactions in the crystal structure are presented in Table 2. A perspective view of the molecular structure, including atom numbering scheme, is shown in Fig. 1, while an illustration of the crystal packing is given with Fig. 2. The diagram in Fig. 3 demonstrates the potential construction principle of the plain host lattice.

The crystal structure of $\mathbf{1 a}$ has the monoclinic space group $P 2{ }_{1} / c$ with one host molecule, two molecules of DMSO and one molecule of $\mathrm{CHCl}_{3}$ in the asymmetric cell unit (Fig. 1). The bond lengths within the buta-1,3-diyne part of $\mathbf{1}$ are 1.432(2)/1.433(2) for $\mathrm{C}\left(\mathrm{sp}^{2}\right)-\mathrm{C}(\mathrm{sp})$, 1.199(2)/1.201(2) for $\mathrm{C} \equiv \mathrm{C}$ and 1.374(2) $\AA$ for the single $\mathrm{C}(\mathrm{sp})-\mathrm{C}(\mathrm{sp})$ bond, and are similar to those found in 1,4-diphenylbutadiyne and its derivatives $(23,24)$. The high degree of molecular association in the crystal structure causes a slight bend of the host molecule along its diacetylene element (25), so that the dihedral angle between the planes of the aromatic rings is $11.5^{\circ}$. The carboxy groups are inclined at angles between $2.7(1)$ and $8.3(2)^{\circ}$ with respect to the plane of the aromatic rings to which they are attached.

It is clear that assembly of the molecules via carboxylic pairing $(9,26)$ would result in a highly expanded and thus presumably too labile structure $(27,28)$. As a possible consequence of this, we did not succeed to grow a crystal of $\mathbf{1}$ in its solvent free state. Instead, the distinctive donor/acceptor character of the crystal components induces a complicated network of noncovalent bonding between molecules. As depicted in Fig. 2, all strong donor atoms of the tetracarboxylic acid are associated in the same fashion with DMSO molecules via $\mathrm{O}-\mathrm{H} \cdots \mathrm{O}$ hydrogen bonds (29) [ $d(\mathrm{O} \cdots \mathrm{O}) 2.598(3)-2.651(3) \AA]$, while a part of the acidic hydrogens of the DMSO molecules are coordinated to the carboxyl oxygens $\mathrm{O}(3), \mathrm{O}(4)$ and $\mathrm{O}(7)$ of $\mathbf{1}$ or fulfil DMSO...DMSO interaction (30). Nevertheless, the donor-acceptor character of the tetracarboxylic acid $\mathbf{1}$ requires the presence of a second solvent species having a complementary coordination behaviour compared with DMSO. This is realized by the chloroform molecule, 
more weakly interacting through $\mathrm{C}=\mathrm{O} \cdots \mathrm{H}-\mathrm{C}(31)$ and $\mathrm{C}=\mathrm{O} \cdots \mathrm{Cl}-\mathrm{C}$ contacts $(32,33)$ to different molecules of 1. In more detail, the hydrogen atom of the chloroform molecule is connected to $\mathrm{O}(5)$ of 1 by a relatively strong $\mathrm{C}-\mathrm{H} \cdots \mathrm{O}=\mathrm{C}$ hydrogen bond $[d(\mathrm{O} \cdots \mathrm{H} 2.20 \AA]$. The observed angular parameters of the $\mathrm{C}=\mathrm{O} \cdots \mathrm{Cl}-\mathrm{C}$ contacts contributing to the chloroform coordination $\left(\mathrm{C}=\mathrm{O} \cdots \mathrm{Cl} 85.6,126.6^{\circ} ; \mathrm{C}-\mathrm{Cl} \cdots \mathrm{O} 158.2,167.9^{\circ}\right)$ agree well with the concept of the so called "electrophil-nucleophil pairing" (34), which considers the oxygen of $\mathrm{C}=\mathrm{O}$ as an "electrophil" approaching the halogen of $\mathrm{C}-\mathrm{X}(\mathrm{X}=\mathrm{Cl}, \mathrm{Br}, \mathrm{I})$ at an angle of $\sim 100^{\circ}$ ("side on"), whereas the nucleophil $\mathrm{X}$ approaches the oxygen of $\mathrm{C}=\mathrm{O}$ at $\sim 165^{\circ}$ ("head on"). From this angle, the solvent molecules are different in their effect for stabilization of the lattice framework. While DMSO does mainly bonding like assist in stabilization of the lattice construction, the chloroform is less effective in this way but, on the contrary, may be regarded a volume stabilizing component as it fills lattice voids left by the $\mathbf{1} \cdot 2$ DMSO network.

A view of the crystal structure in direction of the $b$-axis reveals that the $\mathbf{1}$ molecules, one equivalent of DMSO solvent and the $\mathrm{CHCl}_{3}$ molecules are arranged to corrugated layers whereas the remaining solvent molecules are located between the molecular layers. A more instructive illustration of the lattice framework is shown in Fig. 3, which represents a view along the stacking of plain 1 molecules. In this assembly, the longitudinal axes of molecules of consecutive layers are rotated by nearly $90^{\circ}$. From this it follows that every fourth layer in stacking direction is congruent thus producing an uncongested lattice structure. Nevertheless, the relatively close distance of $3.3 \AA$ between the aromatic residues of consecutive molecules $\mathbf{1}$ suggests that arene stacking (35) has a decisive effect on the stabilization of the lattice structure.

\section{Conclusions}

A new molecular building block 1 comprising two isophthalic acid moieties attached in the 5position to both ends of a rigid rod-like diacetylene unit, which has been synthesized, is shown to create a complex (1:2:1) mixed solvent crystalline framework 1a with DMSO and chloroform as secondary and tertiary components, the structure of which has been solved.

While other tetracarboxylic acids with similar well-defined shapes behave as tectons for the controlled assembly of hydrogen bonded open frameworks rather than a close packed structure $(11,14)$, the present compound 1, although corresponding to this molecular design, behaves markedly different in structure formation under the used condition. This can be attributed to geometric parameters of the molecule leading to a highly expanded labile crystal 
lattice on carboxylic pairing. Hence, as a way out, the molecule uses its secondary mode of synthon formation (26) which is aromatic stacking (35), allowing a partly overlap of the molecules and thus considerable shrinking of the lattice volume. The carboxylic groups being now extremely unsatisfied in terms of their hydrogen donor-acceptor property take the opportunity to interact with the coordinating solvent molecules, giving rise to a close packed structure.

Another line of reasoning is using metal ions strongly coordinating to the carboxylate groups of $\mathbf{1}$ in order to stabilize a porous framework structure (36). Actually, this has become possible as recently demonstrated by the generation and structural solution of a corresponding coordination polymer based on $\mathbf{1}$ and copper(II) (37), opening promising aspects of $\mathbf{1}$ in the actual field of metal-organic-frameworks (MOFs) $(12,13)$. Moreover, due to the molecular shape and functionality, the compound $\mathbf{1}$ may also excite interest as tecton in the topical research area of surface assisted two-dimensional crystal engineering (6,38-41).

\section{Experimental}

\section{Methods and materials}

The melting points (uncorrected) were measured on a hot-stage microscope PHMK (Rapido Dresden). NMR spectra were recorded on a Bruker DPX 400 spectrometer $\left({ }^{1} \mathrm{H} 400,{ }^{13} \mathrm{C} 100\right.$ $\mathrm{MHz}$ ) in solutions using TMS as internal standard. IR spectra were determined on a Nicolet 510 FT-IR spectrometer. MS spectra were obtained using Hewlett-Packard MS 5989A (GC-MS) and Finnigan Mat 8200 (EI-MS) instruments. Elemental analyses were performed on a Heraeus CHN-Rapid analyzer. Thin layer chromatography was carried out using Merck Silica gel $60 \mathrm{~F}_{254}$ on aluminium backed plates. Solvents were purified and dried using standard laboratory procedures (42).

The following reagents were purchased from commercial sources: MEBINOL (Acros Organics) palladiumtriphenylphosphane dichloride (ABCR), copper(II) acetate, copper(I) iodide lithium hydroxide and sodium hydride (60\% in mineral oil) (Aldrich). Dimethyl 5iodoisophthalate was prepared as described in the literature (15). 


\section{Synthesis}

\section{Dimethyl 5-(3-hydroxy-3-methyl-1-butynyl)isophthalate (3)}

A mixture of dimethyl 5-iodoisophthalate (2) (10.0 g, $31.2 \mathrm{mmol})$, 2-methylbut-3-yne-2-ol (MEBINOL, $3.20 \mathrm{~g}, 37.5 \mathrm{mmol}), \mathrm{Pd}\left(\mathrm{PPh}_{3}\right)_{2} \mathrm{Cl}_{2}(180 \mathrm{mg}, 0.26 \mathrm{mmol})$ and $\mathrm{CuI}(40 \mathrm{mg}, 0.21$ mmol $)$ in pyridine $(25 \mathrm{ml})$ and triethylamine $(60 \mathrm{ml})$ under Ar was heated to reflux for $1 \mathrm{~h}$. After cooling to room temperature, the triethylammonium chloride, which has formed, was filtered off using celite and washed with diethyl ether. The filtrate was added dropwise under cooling to $6 \mathrm{~N}$ hydrochloric acid. The aqueous phase was separated and extracted three times with diethyl ether. The combined organic layers were washed with $2 \mathrm{~N}$ hydrochloric acid, aqueous sodium hydrogen carbonate and water, in this sequence, and dried with sodium sulphate. The solvent was evaporated and the crude product crystallized from toluene- $n$-hexane $(1: 1, \mathrm{v} / \mathrm{v})$ to yield $76 \%$ of a white powder: mp $104-106{ }^{\circ} \mathrm{C}$. IR $\left(\mathrm{KBr}, \mathrm{cm}^{-1}\right): 3452(\mathrm{OH}), 3084(\mathrm{C}-\mathrm{H}, \mathrm{Ar}), 2981,2955(\mathrm{C}-\mathrm{H})$, $2231(\mathrm{C} \equiv \mathrm{C}), 1734(\mathrm{C}=\mathrm{O})$, 1636, 1605 (Ar), $1440(\mathrm{C}-\mathrm{H})$, 1347, 1259, 1202, 1176 (C-O), 1005, 917, $866(\mathrm{Ar}) ;{ }^{1} \mathrm{H}$ NMR $\left(\mathrm{CDCl}_{3}\right): \delta 1.63\left(\mathrm{~s}, 6 \mathrm{H}, \mathrm{CCH}_{3}\right), 2.05(\mathrm{~s}, 1 \mathrm{H}, \mathrm{OH}), 3.95\left(\mathrm{~s}, 6 \mathrm{H}, \mathrm{OCH}_{3}\right)$, $8.25\left(\mathrm{~d},{ }^{4} J=1.5 \mathrm{~Hz}, 2 \mathrm{H}, \mathrm{Ar}-H\right), 8.60\left(\mathrm{t},{ }^{4} J=1.5 \mathrm{~Hz}, 1 \mathrm{H}, \mathrm{Ar}-H\right) ;{ }^{13} \mathrm{C} \mathrm{NMR}\left(\mathrm{CDCl}_{3}\right): \delta 31.4$ $\left(\mathrm{CCH}_{3}\right), 52.5\left(\mathrm{OCH}_{3}\right), 65.6\left[C\left(\mathrm{CH}_{3}\right)_{2} \mathrm{OH}\right], 80.3(\mathrm{Ar}-\mathrm{C} \equiv \mathrm{C}), 95.7(\mathrm{Ar}-\mathrm{C} \equiv C), 123.9,130.1,130.9$, $136.6(\mathrm{Ar}-\mathrm{C}), 165.6\left(\mathrm{COOCH}_{3}\right)$. MS (GC): $\mathrm{m} / z$ calcd for $\mathrm{C}_{15} \mathrm{H}_{16} \mathrm{O}_{5}: 276.28$. Found $276\left[\mathrm{M}^{+}\right]$. Anal. calcd for $\mathrm{C}_{15} \mathrm{H}_{16} \mathrm{O}_{5}$ : C, 65.21,; H, 5.84. Found: C, 64.86; H, 5.97\%.

\section{5-Ethynylisophthalic acid (4)}

To a solution of potassium hydroxide (11.6 g, $207.3 \mathrm{mmol})$ in $n$-butanol $(250 \mathrm{ml})$ was added compound 3 (6.0 g, $21.7 \mathrm{mmol})$ and the mixture heated under reflux for $30 \mathrm{~min}$. After cooling to room temperature, the precipitate which has formed was separated and washed with ethanol to yield in $88 \%$ the dipotassium salt of $\mathbf{4}$ as an off-white powder $\left(\mathrm{mp}>350^{\circ} \mathrm{C}\right)$. This was dissolved in water $(20 \mathrm{ml})$ and acidified to $\mathrm{pH} 1$ with $5 \mathrm{~N}$ hydrochloric acid. The precipitate which has formed was separated, washed with water and dried for $4 \mathrm{~h}$ at $50{ }^{\circ} \mathrm{C}$ under vacuum to yield $98 \%$ of a white powder: mp $247-250{ }^{\circ} \mathrm{C}$. IR ( $\left.\mathrm{KBr}, \mathrm{cm}^{-1}\right)$ : 3297 (C-H, ethynyl), 3076 (C-H, Ar), 2983, 2933, 2876 (C-H), 2116 (C $\equiv \mathrm{C}), 1706$ (C=O), 1599 (Ar), 1278, 1246 (C-O), 917, 860 (Ar); ${ }^{1} \mathrm{H}$ NMR ([D $]_{6}$ DMSO): $\delta 4.43$ (s, $\left.1 \mathrm{H}, \mathrm{C} \equiv \mathrm{C}-H\right), 8.18$ (s, $\left.2 \mathrm{H}, \mathrm{Ar}-H\right), 8.47$ (s, $\left.1 \mathrm{H}, \mathrm{Ar}-H\right), 13.49$ (s, 2 $\mathrm{H}, \mathrm{COOH}) ;{ }^{13} \mathrm{C}$ NMR ([D $]$ DMSO): $\delta 81.7(\mathrm{C} \equiv C-\mathrm{H}), 82.7(C \equiv \mathrm{C}-\mathrm{H}), 122.8,130.1,132.1,136.0$ $(\mathrm{Ar}-C), 165.8(\mathrm{COOH}) . \mathrm{MS}(\mathrm{EI}): \mathrm{m} / z$ calcd for $\mathrm{C}_{10} \mathrm{H}_{6} \mathrm{O}_{4}: 190.15$. Found: $189.9\left[\mathrm{M}^{+}\right]$. Anal. calcd for $\mathrm{C}_{10} \mathrm{H}_{6} \mathrm{O}_{4}$ : C, 63.16; $\mathrm{H}, 3.18$. Found: $\mathrm{C}, 62.88 ; \mathrm{H}, 3.42 \%$. 


\section{Dimethyl 5-ethynylisophthalate (5)}

(a) Via esterification of 4: A mixture of the diacid 4 (5.70 g, $30.0 \mathrm{mmol})$ in dry methanol (25 ml) and conc. sulfuric acid $(1.20 \mathrm{~g}, 12.2 \mathrm{mmol})$ was heated to reflux for $5 \mathrm{~h}$ under dry conditions. The most part of the alcohol was evaporated and the residue added to five times the amount of iced water. The organic layer was separated and the aqueous phase extracted three times with diethyl ether. The combined organic layers were washed with conc. aqueous solution of sodium carbonate and water, in this sequence, and dried with sodium sulphate. Evaporation of the solvent and crystallization from ethanol yielded $55 \%$ of colourless needles; mp $134-136{ }^{\circ} \mathrm{C}$ (lit. (19) $130-131^{\circ} \mathrm{C}$ ). Spectroscopic data correspond with the literature (19).

(b) Via deblocking of 3: To a solution of $3(6.0 \mathrm{~g}, 21.7 \mathrm{mmol})$ in dry toluene (300 $\mathrm{ml})$, sodium hydride ( $60 \%$ in mineral oil, $1.56 \mathrm{~g}, 39.0 \mathrm{mmol}$ ) was added and the mixture heated for $1 \mathrm{~h}$ to 75 ${ }^{\circ} \mathrm{C}$. After cooling to room temperature, the mixture was carefully quenched with water. The organic layer was separated, washed with water and dried with sodium sulphate. Evaporation of the solvent and crystallization from ethanol yielded $60 \%$ of the compound.

\section{Tetramethyl 5,5'-(1,3-butadiyne-1,4-diyl)diisophthalate (6)}

A solution of the diester $5(0.50 \mathrm{~g}, 2.30 \mathrm{mmol})$ in pyridine-methanol $(10 \mathrm{ml}, 1: 1$, v/v) was heated for $30 \mathrm{~min}$ under an atmosphere of argon, in order to remove oxygen. After cooling down to room temperature, copper(II) acetate $(0.60 \mathrm{~g}, 3.22 \mathrm{mmol})$ was added and the mixture heated to reflux for $4 \mathrm{~h}$ under argon. The mixture was then cooled to room temperature and dropped slowly into $18 \mathrm{~N}$ sulfuric acid under cooling with ice. The solid which has formed was dissolved in diethyl ether. The ethereal solution was washed with water and dried with sodium sulphate. The solvent was evaporated and the crude product crystallized from acetone-chloroform (1:1, v/v) to yield $88 \%$ of a colourless solid; mp 221-222 ${ }^{\circ} \mathrm{C}$. IR $\left(\mathrm{KBr}, \mathrm{cm}^{-1}\right): 3079,3037,3008(\mathrm{C}-\mathrm{H}$, Ar), 2951 (C-H), 1729 (C=O), 1634, 1595 (Ar), 1438 (C-H), 1331, 1271, 1131, 1110 (C-O), 999, 914, 875 (Ar); ${ }^{1} \mathrm{H}$ NMR $\left(\mathrm{CDCl}_{3}\right) \delta 3.97$ (s, $12 \mathrm{H}, \mathrm{CH}_{3}$ ), 8.37 (s, $4 \mathrm{H}, \mathrm{Ar}-H$ ), 8.67 (s, $2 \mathrm{H}, \mathrm{Ar}-H$ ); ${ }^{13} \mathrm{C} \mathrm{NMR}\left(\mathrm{CDCl}_{3}\right) \delta 52.6\left(\mathrm{CH}_{3}\right), 75.1(\mathrm{C}-\mathrm{C} \equiv C), 80.2 \quad(\mathrm{C}-C \equiv C), 122.6,131.2,131.3,137.4$ (Ar-C), $165.3\left(\mathrm{COOCH}_{3}\right)$; MS (GC): $\mathrm{m} / z$ calcd for $\mathrm{C}_{24} \mathrm{H}_{18} \mathrm{O}_{8}: 434.39$. Found: $434\left[\mathrm{M}^{+}\right]$. Anal. calcd for $\mathrm{C}_{24} \mathrm{H}_{18} \mathrm{O}_{8}$ : C, 66.36; $\mathrm{H}, 4.18$. Found: C, 66.18; $\mathrm{H}, 4.15 \%$.

5,5'-(1,3-Butadiyne-1,4-diyl)diisophthalic acid (1) 
The tetraester $6(0.20 \mathrm{~g}, 0.46 \mathrm{mmol})$ was dissolved in THF $(15 \mathrm{ml})$. Lithium hydroxide $(0.80 \mathrm{~g}$, $19.0 \mathrm{mmol})$ was added and the suspension mixed with water $(4.5 \mathrm{ml})$. The mixture was stirred for $15 \mathrm{~h}$ at room temperature and then diluted with water $(20 \mathrm{ml})$. The solution was acidified with $3 \mathrm{~N}$ hydrochloric acid and the precipitate, which has formed, dissolved with a mixture of diethylether and THF. The ethereal solution was dried with sodium sulphate and evaporated to yield after drying at $100{ }^{\circ} \mathrm{C}$ under vacuum $83 \%$ of a colourless solid: $\mathrm{mp}>350{ }^{\circ} \mathrm{C}$. IR $\left(\mathrm{KBr}, \mathrm{cm}^{-}\right.$ $\left.{ }^{1}\right): 3415$ (br, $\left.\mathrm{H}_{2} \mathrm{O}\right), 3038$ (C-H, Ar), 2637, 2551 (COOH), $1703(\mathrm{C}=\mathrm{O}), 1595,1542,1510$ (Ar), 1142 (C-O), 914 (Ar). ${ }^{1} \mathrm{H}$ NMR ([D $\left.\left.{ }_{6}\right] \mathrm{DMSO}\right): \delta 8.30$ (s, $\left.4 \mathrm{H}, \mathrm{Ar}-H\right), 8.50$ (s, $\left.2 \mathrm{H}, \mathrm{Ar}-H\right), 13.62$ (s, $4 \mathrm{H}, \mathrm{COOH}) ;{ }^{13} \mathrm{C}$ NMR ([D $]$ DMSO): $\delta 74.5(\mathrm{C}-\mathrm{C} \equiv C), 80.6(\mathrm{C}-C \equiv \mathrm{C}), 121.4,131.0,132.3$, 136.6 (Ar-C), $165.6(\mathrm{COOH})$. MS (EI): $\mathrm{m} / z$ calcd for $\mathrm{C}_{20} \mathrm{H}_{10} \mathrm{O}_{8}$ : 378.29. Found: $378.1\left[\mathrm{M}^{+}\right]$. Anal. calcd for $\mathrm{C}_{20} \mathrm{H}_{10} \mathrm{O}_{8} \cdot \mathrm{H}_{2} \mathrm{O}: \mathrm{C}, 60.61 ; \mathrm{H}, 3.05$. Found: C, 60.28; H, $2.93 \%$.

\section{X-ray crystallography}

Single crystals of 1a suitable for X-ray crystallographic analysis were grown from a solution of $\mathbf{1}$ in DMSO-chloroform. Intensity data were collected on a Bruker Kappa APEX II diffractometer with MoK $\alpha$ radiation $(\lambda=0.71073 \AA)$ using $\omega$ - and $\varphi$-scans. Reflections were corrected for background and Lorentz polarization effects. Preliminary structure models were derived by application of direct methods (43) and were refined by full-matrix least squares calculation based on $F^{2}$ for all reflections (43). All hydrogens were included in the models in calculated positions and were refined as constrained to bonding atoms. Analysis of hydrogen bonds was carried out by using the HTAB instruction of the SHELXTL program. Crystallographic data for the structure in this paper have been deposited with the Cambridge Crystallographic Centre as supplementary publication number CCDC-780477. Copies of data can be obtained, free of charge, on application to the Director, CCDC, 12 Union Road, Cambridge CB2 1EZ, UK (Fax: +44-1223-336033, Email: deposit@ccdc.cam.ac.uk).

\section{Acknowledgement}

This work was financially supported by the Deutsche Forschungsgemeinschaft (SPP 1362/1). 


\section{References}

(1) Tiekink, E.R.T.; Vittal, J., Eds. Frontiers in Crystal Engineering; Wiley: Hoboken, 2006.

(2) Braga, D.; Grepioni, F., Eds. Making Crystals by Design: Methods, Techniques and Applications; Wiley-VCH: Weinheim, 2007.

(3) Jones, W.; Rao, J.N.R., Eds. Supramolecular Organization and Materials Design; Cambridge University Press: New York, 2008.

(4) Weber, E. In Comprehensive Supramolecular Chemistry; MacNicol, D.D.; Toda, F.; Bishop, R., Eds.; Elsevier: Oxford, 1996, Vol. 6, pp 535 - 592.

(5) Metrangolo, P.; Resnati, G. In Encyclopedia of Supramolecular Chemistry; Atwood, J.L.; Steed, J.W., Eds.; CRC Press: Boca Raton, FL, 2004, pp 1484 - 1492.

(6) Elemans, J.A.A.W.; Lei, S.; De Feyter, S. Angew. Chem. Int. Ed. 2009, 121, 7434 - 7469.

(7) Burrows, A.D. In Supramolecular Assembly via Hydrogen Bonds I; Mingos, D.M., Ed.; Structure and Bonding, Vol. 108; Springer-Verlag: Berlin-Heidelberg, 2004, pp 55 - 96.

(8) Weber, E.; Czugler, M. In Molecular Inclusion and Molecular Recognition - Clathrates II; Weber, E., Ed.; Topics in Current Chemistry, Vol. 149; Springer-Verlag: BerlinHeidelberg, 1988, pp 45 - 135.

(9) Meléndez, R.E.; Hamilton, A.D. In Design of Organic Solids; Weber, E., Ed.; Topics in Current Chemistry, Vol. 198; Springer-Verlag: Berlin-Heidelberg, 1998, pp 97 - 129.

(10) Kolotuchin, S.V.; Thiessen, P.A.; Fenlon, E.E.; Wilson, S.R.; Loweth, C.H., Zimmerman, S.C. Chem. Eur. J. 1999, 5, 2537 - 2547.

(11) Blunt, M.; Lin, S.; Gimenez-Lopez, C.M.; Schröder, M.; Champness, N.R.; Beton, P.H. Chem. Commun. 2008, 2304 - 2306. 
(12) Batten, S.R.; Neville, S.M.; Turner, D.R. Coordination Polymers; Royal Society of Chemistry: Cambridge, 2009.

(13) Chen, L.; Hong, M.-C. Design and Construction of Coordination Polymers; Wiley-VCH: Weinheim, 2009.

(14) Zhou, H.; Dang, H.; Yi, J.-H.; Nanci, A.; Rochefort, A.; Wuest, J.D. J. Am. Chem. Soc. 2007, 129, $13774-13775$.

(15) Mazik, M.; König, A. J. Org. Chem. 2006, 71, 7854 - 7857.

(16) Doucet, H.; Hierso, J. C. Angew. Chem. Int. Ed. 2007, 46, 834 - 871.

(17) Rafael, C.; Carmen, N. Chem. Rev. 2007, 107, 874 - 922.

(18) Havens, S.J.; Hergenrother, P.M. J. Org. Chem. 1985, 50, 1763 - 1765.

(19) Bhagwat, S.S.; Roland, D.M.; Main, A.J.; Gude, C.; Goldstein, R.; Cohen, D.S.; Dotson, R.; Mathis, J.; Lee, W. Biorg. Med. Chem. Lett. 1992, 2, 1623 - 1626.

(20) Crisp, G.T.; Turner, P. D. Tetrahedron 2000, 56, 8335 - 8344.

(21) Simándi, L.I. In The Chemistry of Functional Groups, Suppl. C; Patai, S.; Rappoport, Z., Eds.; Wiley: New York, 1983, pt 1, pp 529 - 534.

(22) Fedenok, L.G.; Berdnikov, V.M.; Shvartsberg, M.S. J. Org. Chem. USSR 1973, 9, 1806 1809.

(23) Back, S.; Lutz, M.; Spek, A.L.; Lang, H.; van Koten, G J. Organomet. Chem. 2001, $620,227-234$.

(24) Thomas, R.; Mallajyosula, S.S.; Lakshmi, L.; Pati, S.K.; Kulkarni, G.U. J. Mol. Struct. 2009, 922, 46 - 50 . 
(25) Schindler, D.; Eißmann, F.; Weber, E. Org. Biomol. Chem. 2009, 7, 3549 - 3560.

(26) Desiraju, G.R. Angew. Chem. Int. Ed. 1995, 34, 2311 - 2327.

(27) Kitaigorodsky, A.I. Molecular Crystals and Molecules; Academic Press: New York, 1973.

(28) Kitaigorodsky, A.I. Organic Chemical Crystallography; Consultant Bureau: New York, 1961.

(29) Csöregh, I.; Czugler, M.; Ertan, A.; Weber, E.; Ahrendt, J. J. Incl. Phenom. 1990, 8, 275 $-287$.

(30) Ruffani, A.; Seichter, W.; Weber, E. J. Incl. Phenom. Macrocyl. Chem. 2010 (DOI 10.1007/s10847-010-9850-0).

(31) Desiraju, G.R.; Steiner, T. The Weak Hydrogen Bond; IUCr Monographs on Crystallography, Vol. 9; Oxford University Press: New York, 1999, pp 29 - 121.

(32) Rissanen, K. CrystEngComm 2008, 10, 1107 - 1113.

(33) Metrangolo, P.; Meyer, M.; Pilati, T.; Resnati, G.; Terraneo, G. Angew. Chem. Int. Ed. 2008, $120,6206-6220$.

(34) Ramasubbu, N.; Parthasarathy, R.; Murray-Rust, P. J. Am. Chem. Soc. 1986, 108, 4308 4314.

(35) Dance, I. In Encyclopedia of Supramolecular Chemistry; Atwood, J.L.; Steed, W.J., Eds.; CRC Press: Boca Raton, FL, 2004, pp 1076 - 1092.

(36) Hausdorf, S.; Seichter, W.; Weber, E.; Mertens, F.O.R.L., Dalton Trans. 2009, 1107 1113. 
(37) Böhle, T.; Schindler, D.; Hauptvogel, I.M.; Mertens, F.O.R.L.; Weber, E.; paper in preparation .

(38) Bonifazi, D.; Mohnani, S.; Llanes-Pallas, A. Chem. Eur. J. 2009, 15, 7004 - 7025.

(39) Payer, D.; Comisso, A.; Dmitriev, A.; Strunskus, T.; Lin, N.; Wöll, C.; De Vita, A.; Barth, J.V.; Kern, K. Chem. Eur. J. 2007, 13, 3900 - 3906.

(40) Kampschulte, L.; Lackinger, M.; Maier, A.-K.; Kishore, R.S.K.; Griessl, S.; Schmittel, M.; Heckl, W.M. J. Phys. Chem. 2006, B110, 10829 - 10836.

(41) Schütte, M.; Stolle, C.; Kurth, D.G. Supramol. Chem. 2003, 15, 549 - 555.

(42) Leonard, L.; Lugo, B.; Procter, G. Praxis der Organischen Chemie; VCH: Weinheim, Germany, 1994, pp 53 - 68.

(43) Sheldrick, G.M. Acta Crystallogr. 2008, A64, 112 - 122. 


\section{Captions to Figures}

Scheme 1. Chemical formulas of the compounds studied.

Scheme 2. Synthetic pathway for preparation of compound $\mathbf{1}$.

Figure 1. Perspective view of the asymmetric unit of $\mathbf{1 a}\left(\mathbf{1} \cdot 2 \mathrm{DMSO} \cdot \mathrm{CHCl}_{3}\right)$. Thermal ellipsoids are drawn at 50\% probability level. Broken lines represent hydrogen bonds.

Figure 2. Packing excerpt of 1a showing the mode of intermolecular interactions. Chlorine atoms are displayed as cross-hatched circles, oxygen atoms as dotted and sulfur atoms as shaded circles. Broken lines represent hydrogen bond type interactions.

Figure 3. Illustration of the plain lattice of 1 (excluding solvent molecules) viewed along the crystallographic $a$-axis. Oxygen atoms are displayed as shaded circles. Only the hydrogens of the carboxy groups are displayed for clarity. 


\section{Unusual mixed solvent supramolecular crystal framework formed of a new tecton-like tetracarboxylic building block $\dagger$}

Ines M. Hauptvogel, \$ Wilhelm Seichter, and Edwin Weber*

Institut für Organische Chemie, Technische Universität Bergakademie Freiberg, Leipziger Str. 29, D-09596 Freiberg/Sachs., Germany

+ Dedicated to the late Prof. Yurii A. Simonov, Institute of Applied Physics, Academy of Sciences of Moldova, Kishinev, Moldova

* Present address: Institut für Anorganische Chemie der TU Dresden, Helmholtzstr. 10, D-01069 Dresden, Germany

* Corresponding author. Email: Edwin.weber@chemie.tu-freiberg.de 


\begin{abstract}
A new tecton-like tetracarboxylic compound $\mathbf{1}$ featuring two isophthalic acid groups attached to both ends of a rigid 1,3-butadiyne spacer unit is synthesized using acetylene blocking/deblocking and coupling techniques. Crystallization of $\mathbf{1}$ from DMSO-chloroform solution gives rise to the formation of an unusual mixed solvent crystalline framework structure 1a containing DMSO and chloroform as secondary and tertiary components in 1:2:1 stoichiometric ratio. The X-ray crystal structure of 1a shows interesting stacking mode and hydrogen-bonded, three-dimensional network architecture with the two solvent species being involved in different behaviour pattern.
\end{abstract}

Keywords: tetracarboxylic acid; dimethyl sulfoxide; chloroform; crystalline complex; x-ray crystal structure

\title{
Introduction
}

Carboxylic acids featuring a well defined shape have developed to a key position in the controlled assembly of supramolecular systems with a variety of uses in different branches of crystal engineering (1-3). This covers the carboxylic acids as hosts for crystalline inclusion formation (4) as well as their functional behaviour of a tecton (5), allowing the targeted formation of two- and three-dimensional hydrogen bond stabilized network structures $(6,7)$, although the carboxylic building blocks are brought different into action in these particular fields. While in the object of crystalline host-guest complexation the carboxylic groups are primarily intended for hydrogen bonding to the molecular guest species (8), they are used in the network construction for cyclic hydrogen-bonded pair formation (6,7,9-11). Moreover, rigid oligocarboxylic acid molecules are also very efficiently employed as coordinative linkers in the formation of open organic-inorganic hybrid frameworks (MOFs) $(12,13)$. This implies that for hydrogen-bonded guest inclusion the carboxylic groups are endo in the attachment to the host molecule but at peripheral site in the tectones and linkers. With reference to the tectons, tetracarboxylic acids composed of two isophthalic acid groups connected at both ends of a linear spacer moiety, varying in the length, have been studied in their preference towards the formation of close packed, open parallel or Kagomé networks $(11,14)$. In the case of biphenyl-3,3',5,5'- 
tetracarboxylic acid (two directly connected isophthalic acid groups), open parallel network formation is observed in the solid state structure, whereas the use of a very elongated 1,4phenylene-bis(ethynylene) spacer unit between the isophthalic acid moieties produces a Kagomé assembly of the respective molecules adsorbed on highly oriented pyrolytic graphite, and the intermediate compound with a short ethynylene spacer results in the formation of a mixed pattern containing small areas of the two different motifs (14). Thus the length of the spacer unit in the tetracarboxylic molecules is shown to exert a distinct influence on the network structure to be formed.

Referring to the present compound 1 (Scheme 1), we describe the synthesis of a new member of this particular substance class of bisisophthalic acids featuring with the 1,3butadiyne-1,4-diyl spacer unit a molecule of medium length. Crystallization of $\mathbf{1}$ from a solvent mixture of DMSO and chloroform yielded an interesting stacking mode and hydrogen-bonded, three-dimensional mixed solvent containing network architecture of 1a with the two solvent species being involved in different behaviour pattern, the structure of which is reported and discussed under the specific circumstances.

\section{Results and discussion}

\section{Synthesis}

Synthesis of the title compound $\mathbf{1}$ was performed as specified in Scheme 2. This involves reaction of the starting compound dimethyl 5-iodoisophthalate (2) (15) with MEBYNOL using a Pd-catalyzed Songashira coupling procedure $(16,17)$ to give the blocked acetylenic diester $\mathbf{3}$. The 5-ethynylisophthalic acid (4) was prepared from 3 via removal of the blocking group with $\mathrm{KOH}$ in $n-\mathrm{BuOH}$, yielding as an intermediate the dipotassium salt of $\mathbf{4}$, which was converted into $\mathbf{4}$ by the reaction with hydrochloric acid. Sulphuric acid catalyzed esterification of $\mathbf{4}$ with methanol gave the corresponding diester $\mathbf{5}$. Alternatively, the diester $\mathbf{5}$ could also be obtained in a selective single-step deblocking reaction from 3 using sodium hydride in toluene (18). Actually, the compound $\mathbf{5}$ has already been described in the literature applying a similar synthetic route $(19,20)$ but being based on the rather costly TMS-acetylene instead of the cheaper MEBYNOL as the blocking reagent. The diester 5 was subjected to an Eglinton coupling reaction $(21,22)$ with copper(II) acetate in pyridine-methanol to produce the tetraester 6. This ester was 


\section{$X$-ray structural study}

Crystallization of the tetracarboxylic acid $\mathbf{1}$ from a solvent mixture of dimethylsulfoxide and chloroform yields a ternary complex 1a containing 1, DMSO and chloroform in the stoichiometric ratio 1:2:1. Crystallographic data and selected refinement parameters of the structure are summarized in Table 1. Information regarding possible non-covalent interactions in the crystal structure are presented in Table 2. A perspective view of the molecular structure, including atom numbering scheme, is shown in Fig. 1, while an illustration of the crystal packing is given with Fig. 2. The diagram in Fig. 3 demonstrates the potential construction principle of the plain host lattice.

The crystal structure of $\mathbf{1 a}$ has the monoclinic space group $P 2{ }_{1} / c$ with one host molecule, two molecules of DMSO and one molecule of $\mathrm{CHCl}_{3}$ in the asymmetric cell unit (Fig. 1). The bond lengths within the buta-1,3-diyne part of $\mathbf{1}$ are 1.432(2)/1.433(2) for $\mathrm{C}\left(\mathrm{sp}^{2}\right)-\mathrm{C}(\mathrm{sp})$, $1.199(2) / 1.201(2)$ for $\mathrm{C} \equiv \mathrm{C}$ and 1.374(2) $\AA$ for the single $\mathrm{C}(\mathrm{sp})-\mathrm{C}(\mathrm{sp})$ bond, and are similar to those found in 1,4-diphenylbutadiyne and its derivatives $(23,24)$. The high degree of molecular association in the crystal structure causes a slight bend of the host molecule along its diacetylene element (25), so that the dihedral angle between the planes of the aromatic rings is $11.5^{\circ}$. The carboxy groups are inclined at angles between $2.7(1)$ and $8.3(2)^{\circ}$ with respect to the plane of the aromatic rings to which they are attached.

It is clear that assembly of the molecules via carboxylic pairing $(9,26)$ would result in a highly expanded and thus presumably too labile structure $(27,28)$. As a possible consequence of this, we did not succeed to grow a crystal of $\mathbf{1}$ in its solvent free state. Instead, the distinctive donor/acceptor character of the crystal components induces a complicated network of noncovalent bonding between molecules. As depicted in Fig. 2, all strong donor atoms of the tetracarboxylic acid are associated in the same fashion with DMSO molecules via $\mathrm{O}-\mathrm{H} \cdots \mathrm{O}$ hydrogen bonds (29) $[d(\mathrm{O} \cdots \mathrm{O}) 2.598(3)-2.651(3) \AA]$, while a part of the acidic hydrogens of the DMSO molecules are coordinated to the carboxyl oxygens $\mathrm{O}(3), \mathrm{O}(4)$ and $\mathrm{O}(7)$ of 1 or fulfil DMSO...DMSO interaction (30). Nevertheless, the donor-acceptor character of the tetracarboxylic acid 1 requires the presence of a second solvent species having a complementary coordination behaviour compared with DMSO. This is realized by the chloroform molecule, 
more weakly interacting through $\mathrm{C}=\mathrm{O} \cdots \mathrm{H}-\mathrm{C}(31)$ and $\mathrm{C}=\mathrm{O} \cdots \mathrm{Cl}-\mathrm{C}$ contacts $(32,33)$ to different molecules of 1. In more detail, the hydrogen atom of the chloroform molecule is connected to $\mathrm{O}(5)$ of 1 by a relatively strong $\mathrm{C}-\mathrm{H} \cdots \mathrm{O}=\mathrm{C}$ hydrogen bond $[d(\mathrm{O} \cdots \mathrm{H} 2.20 \AA]$. The observed angular parameters of the $\mathrm{C}=\mathrm{O} \cdots \mathrm{Cl}-\mathrm{C}$ contacts contributing to the chloroform coordination $\left(\mathrm{C}=\mathrm{O} \cdots \mathrm{Cl} 85.6,126.6^{\circ} ; \mathrm{C}-\mathrm{Cl} \cdots \mathrm{O} 158.2,167.9^{\circ}\right)$ agree well with the concept of the so called "electrophil-nucleophil pairing" (34), which considers the oxygen of $\mathrm{C}=\mathrm{O}$ as an "electrophil" approaching the halogen of $\mathrm{C}-\mathrm{X}(\mathrm{X}=\mathrm{Cl}, \mathrm{Br}, \mathrm{I})$ at an angle of $\sim 100^{\circ}$ ("side on"), whereas the nucleophil $\mathrm{X}$ approaches the oxygen of $\mathrm{C}=\mathrm{O}$ at $\sim 165^{\circ}$ ("head on"). From this angle, the solvent molecules are different in their effect for stabilization of the lattice framework. While DMSO does mainly bonding like assist in stabilization of the lattice construction, the chloroform is less effective in this way but, on the contrary, may be regarded a volume stabilizing component as it fills lattice voids left by the $1 \cdot 2$ DMSO network.

A view of the crystal structure in direction of the $b$-axis reveals that the $\mathbf{1}$ molecules, one equivalent of DMSO solvent and the $\mathrm{CHCl}_{3}$ molecules are arranged to corrugated layers whereas the remaining solvent molecules are located between the molecular layers. A more instructive illustration of the lattice framework is shown in Fig. 3, which represents a view along the stacking of plain 1 molecules. In this assembly, the longitudinal axes of molecules of consecutive layers are rotated by nearly $90^{\circ}$. From this it follows that every fourth layer in stacking direction is congruent thus producing an uncongested lattice structure. Nevertheless, the relatively close distance of $3.3 \AA$ between the aromatic residues of consecutive molecules 1 suggests that arene stacking (35) has a decisive effect on the stabilization of the lattice structure.

\section{Conclusions}

A new molecular building block 1 comprising two isophthalic acid moieties attached in the 5position to both ends of a rigid rod-like diacetylene unit, which has been synthesized, is shown to create a complex (1:2:1) mixed solvent crystalline framework 1a with DMSO and chloroform as secondary and tertiary components, the structure of which has been solved.

While other tetracarboxylic acids with similar well-defined shapes behave as tectons for the controlled assembly of hydrogen bonded open frameworks rather than a close packed structure $(11,14)$, the present compound $\mathbf{1}$, although corresponding to this molecular design, behaves markedly different in structure formation under the used condition. This can be attributed to geometric parameters of the molecule leading to a highly expanded labile crystal 
lattice on carboxylic pairing. Hence, as a way out, the molecule uses its secondary mode of synthon formation (26) which is aromatic stacking (35), allowing a partly overlap of the molecules and thus considerable shrinking of the lattice volume. The carboxylic groups being now extremely unsatisfied in terms of their hydrogen donor-acceptor property take the opportunity to interact with the coordinating solvent molecules, giving rise to a close packed structure.

Another line of reasoning is using metal ions strongly coordinating to the carboxylate groups of $\mathbf{1}$ in order to stabilize a porous framework structure (36). Actually, this has become possible as recently demonstrated by the generation and structural solution of a corresponding coordination polymer based on 1 and copper(II) (37), opening promising aspects of $\mathbf{1}$ in the actual field of metal-organic-frameworks (MOFs) $(12,13)$. Moreover, due to the molecular shape and functionality, the compound $\mathbf{1}$ may also excite interest as tecton in the topical research area of surface assisted two-dimensional crystal engineering (6,38-41).

\section{Experimental}

\section{Methods and materials}

The melting points (uncorrected) were measured on a hot-stage microscope PHMK (Rapido Dresden). NMR spectra were recorded on a Bruker DPX 400 spectrometer $\left({ }^{1} \mathrm{H} 400,{ }^{13} \mathrm{C} 100\right.$ $\mathrm{MHz}$ ) in solutions using TMS as internal standard. IR spectra were determined on a Nicolet 510 FT-IR spectrometer. MS spectra were obtained using Hewlett-Packard MS 5989A (GC-MS) and Finnigan Mat 8200 (EI-MS) instruments. Elemental analyses were performed on a Heraeus CHN-Rapid analyzer. Thin layer chromatography was carried out using Merck Silica gel $60 \mathrm{~F}_{254}$ on aluminium backed plates. Solvents were purified and dried using standard laboratory procedures (42).

The following reagents were purchased from commercial sources: MEBINOL (Acros Organics) palladiumtriphenylphosphane dichloride (ABCR), copper(II) acetate, copper(I) iodide lithium hydroxide and sodium hydride (60\% in mineral oil) (Aldrich). Dimethyl 5iodoisophthalate was prepared as described in the literature (15). 


\section{Synthesis}

\section{Dimethyl 5-(3-hydroxy-3-methyl-1-butynyl)isophthalate (3)}

A mixture of dimethyl 5-iodoisophthalate (2) (10.0 g, $31.2 \mathrm{mmol})$, 2-methylbut-3-yne-2-ol (MEBINOL, $3.20 \mathrm{~g}, 37.5 \mathrm{mmol}), \mathrm{Pd}\left(\mathrm{PPh}_{3}\right)_{2} \mathrm{Cl}_{2}(180 \mathrm{mg}, 0.26 \mathrm{mmol})$ and $\mathrm{CuI}(40 \mathrm{mg}, 0.21$ mmol $)$ in pyridine $(25 \mathrm{ml})$ and triethylamine $(60 \mathrm{ml})$ under Ar was heated to reflux for $1 \mathrm{~h}$. After cooling to room temperature, the triethylammonium chloride, which has formed, was filtered off using celite and washed with diethyl ether. The filtrate was added dropwise under cooling to $6 \mathrm{~N}$ hydrochloric acid. The aqueous phase was separated and extracted three times with diethyl ether. The combined organic layers were washed with $2 \mathrm{~N}$ hydrochloric acid, aqueous sodium hydrogen carbonate and water, in this sequence, and dried with sodium sulphate. The solvent was evaporated and the crude product crystallized from toluene- $n$-hexane $(1: 1, \mathrm{v} / \mathrm{v})$ to yield $76 \%$ of a white powder: mp $104-106{ }^{\circ} \mathrm{C}$. IR $\left(\mathrm{KBr}, \mathrm{cm}^{-1}\right)$ : $3452(\mathrm{OH}), 3084(\mathrm{C}-\mathrm{H}, \mathrm{Ar}), 2981,2955(\mathrm{C}-\mathrm{H})$, $2231(\mathrm{C} \equiv \mathrm{C}), 1734(\mathrm{C}=\mathrm{O})$, 1636, 1605 (Ar), $1440(\mathrm{C}-\mathrm{H})$, 1347, 1259, 1202, 1176 (C-O), 1005, 917, 866 (Ar); ${ }^{1} \mathrm{H}$ NMR $\left(\mathrm{CDCl}_{3}\right): \delta 1.63\left(\mathrm{~s}, 6 \mathrm{H}, \mathrm{CCH}_{3}\right), 2.05(\mathrm{~s}, 1 \mathrm{H}, \mathrm{OH}), 3.95\left(\mathrm{~s}, 6 \mathrm{H}, \mathrm{OCH}_{3}\right)$, $8.25\left(\mathrm{~d},{ }^{4} J=1.5 \mathrm{~Hz}, 2 \mathrm{H}, \mathrm{Ar}-H\right), 8.60\left(\mathrm{t},{ }^{4} J=1.5 \mathrm{~Hz}, 1 \mathrm{H}, \mathrm{Ar}-H\right) ;{ }^{13} \mathrm{C} \mathrm{NMR}\left(\mathrm{CDCl}_{3}\right): \delta 31.4$ $\left(\mathrm{CCH}_{3}\right), 52.5\left(\mathrm{OCH}_{3}\right), 65.6\left[C\left(\mathrm{CH}_{3}\right)_{2} \mathrm{OH}\right], 80.3(\mathrm{Ar}-\mathrm{C} \equiv \mathrm{C}), 95.7(\mathrm{Ar}-\mathrm{C} \equiv C), 123.9,130.1,130.9$, $136.6(\mathrm{Ar}-\mathrm{C}), 165.6\left(\mathrm{COOCH}_{3}\right)$. MS (GC): $\mathrm{m} / z$ calcd for $\mathrm{C}_{15} \mathrm{H}_{16} \mathrm{O}_{5}: 276.28$. Found $276\left[\mathrm{M}^{+}\right]$. Anal. calcd for $\mathrm{C}_{15} \mathrm{H}_{16} \mathrm{O}_{5}$ : C, 65.21,; H, 5.84. Found: C, 64.86; H, 5.97\%.

\section{5-Ethynylisophthalic acid (4)}

To a solution of potassium hydroxide (11.6 g, $207.3 \mathrm{mmol})$ in $n$-butanol $(250 \mathrm{ml})$ was added compound 3 (6.0 g, $21.7 \mathrm{mmol})$ and the mixture heated under reflux for $30 \mathrm{~min}$. After cooling to room temperature, the precipitate which has formed was separated and washed with ethanol to yield in $88 \%$ the dipotassium salt of $\mathbf{4}$ as an off-white powder $\left(\mathrm{mp}>350^{\circ} \mathrm{C}\right)$. This was dissolved in water $(20 \mathrm{ml})$ and acidified to $\mathrm{pH} 1$ with $5 \mathrm{~N}$ hydrochloric acid. The precipitate which has formed was separated, washed with water and dried for $4 \mathrm{~h}$ at $50{ }^{\circ} \mathrm{C}$ under vacuum to yield $98 \%$ of a white powder: mp $247-250{ }^{\circ} \mathrm{C}$. IR ( $\left.\mathrm{KBr}, \mathrm{cm}^{-1}\right)$ : 3297 (C-H, ethynyl), 3076 (C-H, Ar), 2983, 2933, 2876 (C-H), 2116 (C $\equiv \mathrm{C}), 1706$ (C=O), 1599 (Ar), 1278, 1246 (C-O), 917, 860 (Ar); ${ }^{1} \mathrm{H}$ NMR ([D $]_{6}$ DMSO): $\delta 4.43$ (s, $\left.1 \mathrm{H}, \mathrm{C} \equiv \mathrm{C}-H\right), 8.18$ (s, $\left.2 \mathrm{H}, \mathrm{Ar}-H\right), 8.47$ (s, $\left.1 \mathrm{H}, \mathrm{Ar}-H\right), 13.49$ (s, 2 $\mathrm{H}, \mathrm{COOH}) ;{ }^{13} \mathrm{C}$ NMR ([D $]$ DMSO): $\delta 81.7(\mathrm{C} \equiv C-\mathrm{H}), 82.7(C \equiv \mathrm{C}-\mathrm{H}), 122.8,130.1,132.1,136.0$ $(\mathrm{Ar}-C), 165.8(\mathrm{COOH}) . \mathrm{MS}(\mathrm{EI}): \mathrm{m} / z$ calcd for $\mathrm{C}_{10} \mathrm{H}_{6} \mathrm{O}_{4}: 190.15$. Found: $189.9\left[\mathrm{M}^{+}\right]$. Anal. calcd for $\mathrm{C}_{10} \mathrm{H}_{6} \mathrm{O}_{4}$ : C, 63.16; $\mathrm{H}, 3.18$. Found: $\mathrm{C}, 62.88 ; \mathrm{H}, 3.42 \%$. 


\section{Dimethyl 5-ethynylisophthalate (5)}

(a) Via esterification of 4: A mixture of the diacid 4 (5.70 g, $30.0 \mathrm{mmol})$ in dry methanol (25 ml) and conc. sulfuric acid $(1.20 \mathrm{~g}, 12.2 \mathrm{mmol})$ was heated to reflux for $5 \mathrm{~h}$ under dry conditions. The most part of the alcohol was evaporated and the residue added to five times the amount of iced water. The organic layer was separated and the aqueous phase extracted three times with diethyl ether. The combined organic layers were washed with conc. aqueous solution of sodium carbonate and water, in this sequence, and dried with sodium sulphate. Evaporation of the solvent and crystallization from ethanol yielded $55 \%$ of colourless needles; mp $134-136{ }^{\circ} \mathrm{C}$ (lit. (19) $130-131^{\circ} \mathrm{C}$ ). Spectroscopic data correspond with the literature (19).

(b) Via deblocking of 3: To a solution of $3(6.0 \mathrm{~g}, 21.7 \mathrm{mmol})$ in dry toluene (300 $\mathrm{ml})$, sodium hydride ( $60 \%$ in mineral oil, $1.56 \mathrm{~g}, 39.0 \mathrm{mmol}$ ) was added and the mixture heated for $1 \mathrm{~h}$ to 75 ${ }^{\circ} \mathrm{C}$. After cooling to room temperature, the mixture was carefully quenched with water. The organic layer was separated, washed with water and dried with sodium sulphate. Evaporation of the solvent and crystallization from ethanol yielded $60 \%$ of the compound.

\section{Tetramethyl 5,5'-(1,3-butadiyne-1,4-diyl)diisophthalate (6)}

A solution of the diester $5(0.50 \mathrm{~g}, 2.30 \mathrm{mmol})$ in pyridine-methanol $(10 \mathrm{ml}, 1: 1$, v/v) was heated for $30 \mathrm{~min}$ under an atmosphere of argon, in order to remove oxygen. After cooling down to room temperature, copper(II) acetate $(0.60 \mathrm{~g}, 3.22 \mathrm{mmol})$ was added and the mixture heated to reflux for $4 \mathrm{~h}$ under argon. The mixture was then cooled to room temperature and dropped slowly into $18 \mathrm{~N}$ sulfuric acid under cooling with ice. The solid which has formed was dissolved in diethyl ether. The ethereal solution was washed with water and dried with sodium sulphate. The solvent was evaporated and the crude product crystallized from acetone-chloroform (1:1, v/v) to yield $88 \%$ of a colourless solid; mp 221-222 ${ }^{\circ} \mathrm{C}$. IR $\left(\mathrm{KBr}, \mathrm{cm}^{-1}\right): 3079,3037,3008(\mathrm{C}-\mathrm{H}$, Ar), 2951 (C-H), 1729 (C=O), 1634, 1595 (Ar), 1438 (C-H), 1331, 1271, 1131, 1110 (C-O), 999, 914, 875 (Ar); ${ }^{1} \mathrm{H}$ NMR $\left(\mathrm{CDCl}_{3}\right) \delta 3.97$ (s, $12 \mathrm{H}, \mathrm{CH}_{3}$ ), 8.37 (s, $4 \mathrm{H}, \mathrm{Ar}-H$ ), 8.67 (s, $2 \mathrm{H}, \mathrm{Ar}-H$ ); ${ }^{13} \mathrm{C} \mathrm{NMR}\left(\mathrm{CDCl}_{3}\right) \delta 52.6\left(\mathrm{CH}_{3}\right), 75.1(\mathrm{C}-\mathrm{C} \equiv C), 80.2 \quad(\mathrm{C}-C \equiv C), 122.6,131.2,131.3,137.4$ (Ar-C), $165.3\left(\mathrm{COOCH}_{3}\right)$; MS (GC): $\mathrm{m} / z$ calcd for $\mathrm{C}_{24} \mathrm{H}_{18} \mathrm{O}_{8}: 434.39$. Found: $434\left[\mathrm{M}^{+}\right]$. Anal. calcd for $\mathrm{C}_{24} \mathrm{H}_{18} \mathrm{O}_{8}$ : C, 66.36; $\mathrm{H}, 4.18$. Found: C, 66.18; $\mathrm{H}, 4.15 \%$.

5,5'-(1,3-Butadiyne-1,4-diyl)diisophthalic acid (1) 
The tetraester $6(0.20 \mathrm{~g}, 0.46 \mathrm{mmol})$ was dissolved in THF $(15 \mathrm{ml})$. Lithium hydroxide $(0.80 \mathrm{~g}$, $19.0 \mathrm{mmol})$ was added and the suspension mixed with water $(4.5 \mathrm{ml})$. The mixture was stirred for $15 \mathrm{~h}$ at room temperature and then diluted with water $(20 \mathrm{ml})$. The solution was acidified with $3 \mathrm{~N}$ hydrochloric acid and the precipitate, which has formed, dissolved with a mixture of diethylether and THF. The ethereal solution was dried with sodium sulphate and evaporated to yield after drying at $100{ }^{\circ} \mathrm{C}$ under vacuum $83 \%$ of a colourless solid: $\mathrm{mp}>350^{\circ} \mathrm{C}$. IR $\left(\mathrm{KBr}, \mathrm{cm}^{-}\right.$ $\left.{ }^{1}\right): 3415$ (br, $\left.\mathrm{H}_{2} \mathrm{O}\right), 3038$ (C-H, Ar), 2637, 2551 (COOH), $1703(\mathrm{C}=\mathrm{O}), 1595,1542,1510$ (Ar), 1142 (C-O), 914 (Ar). ${ }^{1} \mathrm{H}$ NMR ([D $\left.\left.{ }_{6}\right] \mathrm{DMSO}\right): \delta 8.30$ (s, $\left.4 \mathrm{H}, \mathrm{Ar}-H\right), 8.50$ (s, $\left.2 \mathrm{H}, \mathrm{Ar}-H\right), 13.62$ $(\mathrm{s}, 4 \mathrm{H}, \mathrm{COOH}) ;{ }^{13} \mathrm{C}$ NMR ([D $]$ DMSO): $\delta 74.5(\mathrm{C}-\mathrm{C} \equiv C), 80.6(\mathrm{C}-C \equiv \mathrm{C}), 121.4,131.0,132.3$, 136.6 (Ar-C), $165.6(\mathrm{COOH})$. MS (EI): $\mathrm{m} / z$ calcd for $\mathrm{C}_{20} \mathrm{H}_{10} \mathrm{O}_{8}$ : 378.29. Found: $378.1\left[\mathrm{M}^{+}\right]$. Anal. calcd for $\mathrm{C}_{20} \mathrm{H}_{10} \mathrm{O}_{8} \cdot \mathrm{H}_{2} \mathrm{O}: \mathrm{C}, 60.61 ; \mathrm{H}, 3.05$. Found: C, 60.28; H, $2.93 \%$.

\section{X-ray crystallography}

Single crystals of 1a suitable for X-ray crystallographic analysis were grown from a solution of $\mathbf{1}$ in DMSO-chloroform. Intensity data were collected on a Bruker Kappa APEX II diffractometer with MoK $\alpha$ radiation $(\lambda=0.71073 \AA)$ using $\omega$ - and $\varphi$-scans. Reflections were corrected for background and Lorentz polarization effects. Preliminary structure models were derived by application of direct methods (43) and were refined by full-matrix least squares calculation based on $F^{2}$ for all reflections (43). All hydrogens were included in the models in calculated positions and were refined as constrained to bonding atoms. Analysis of hydrogen bonds was carried out by using the HTAB instruction of the SHELXTL program. Crystallographic data for the structure in this paper have been deposited with the Cambridge Crystallographic Centre as supplementary publication number CCDC-780477. Copies of data can be obtained, free of charge, on application to the Director, CCDC, 12 Union Road, Cambridge CB2 1EZ, UK (Fax: +44-1223-336033, Email: deposit@ccdc.cam.ac.uk).

\section{Acknowledgement}

This work was financially supported by the Deutsche Forschungsgemeinschaft (SPP 1362/1). 


\section{References}

(1) Tiekink, E.R.T.; Vittal, J., Eds. Frontiers in Crystal Engineering; Wiley: Hoboken, 2006.

(2) Braga, D.; Grepioni, F., Eds. Making Crystals by Design: Methods, Techniques and Applications; Wiley-VCH: Weinheim, 2007.

(3) Jones, W.; Rao, J.N.R., Eds. Supramolecular Organization and Materials Design; Cambridge University Press: New York, 2008.

(4) Weber, E. In Comprehensive Supramolecular Chemistry; MacNicol, D.D.; Toda, F.; Bishop, R., Eds.; Elsevier: Oxford, 1996, Vol. 6, pp 535 - 592.

(5) Metrangolo, P.; Resnati, G. In Encyclopedia of Supramolecular Chemistry; Atwood, J.L.; Steed, J.W., Eds.; CRC Press: Boca Raton, FL, 2004, pp 1484 - 1492.

(6) Elemans, J.A.A.W.; Lei, S.; De Feyter, S. Angew. Chem. Int. Ed. 2009, 121, 7434 - 7469.

(7) Burrows, A.D. In Supramolecular Assembly via Hydrogen Bonds I; Mingos, D.M., Ed.; Structure and Bonding, Vol. 108; Springer-Verlag: Berlin-Heidelberg, 2004, pp 55 - 96.

(8) Weber, E.; Czugler, M. In Molecular Inclusion and Molecular Recognition - Clathrates II; Weber, E., Ed.; Topics in Current Chemistry, Vol. 149; Springer-Verlag: BerlinHeidelberg, 1988, pp 45 - 135.

(9) Meléndez, R.E.; Hamilton, A.D. In Design of Organic Solids; Weber, E., Ed.; Topics in Current Chemistry, Vol. 198; Springer-Verlag: Berlin-Heidelberg, 1998, pp 97 - 129.

(10) Kolotuchin, S.V.; Thiessen, P.A.; Fenlon, E.E.; Wilson, S.R.; Loweth, C.H., Zimmerman, S.C. Chem. Eur. J. 1999, 5, 2537 - 2547.

(11) Blunt, M.; Lin, S.; Gimenez-Lopez, C.M.; Schröder, M.; Champness, N.R.; Beton, P.H. Chem. Commun. 2008, 2304 - 2306. 
(12) Batten, S.R.; Neville, S.M.; Turner, D.R. Coordination Polymers; Royal Society of Chemistry: Cambridge, 2009.

(13) Chen, L.; Hong, M.-C. Design and Construction of Coordination Polymers; Wiley-VCH: Weinheim, 2009.

(14) Zhou, H.; Dang, H.; Yi, J.-H.; Nanci, A.; Rochefort, A.; Wuest, J.D. J. Am. Chem. Soc. 2007, 129, $13774-13775$.

(15) Mazik, M.; König, A. J. Org. Chem. 2006, 71, 7854 - 7857.

(16) Doucet, H.; Hierso, J. C. Angew. Chem. Int. Ed. 2007, 46, 834 - 871.

(17) Rafael, C.; Carmen, N. Chem. Rev. 2007, 107, 874 - 922.

(18) Havens, S.J.; Hergenrother, P.M. J. Org. Chem. 1985, 50, 1763 - 1765.

(19) Bhagwat, S.S.; Roland, D.M.; Main, A.J.; Gude, C.; Goldstein, R.; Cohen, D.S.; Dotson, R.; Mathis, J.; Lee, W. Biorg. Med. Chem. Lett. 1992, 2, 1623 - 1626.

(20) Crisp, G.T.; Turner, P. D. Tetrahedron 2000, 56, 8335 - 8344.

(21) Simándi, L.I. In The Chemistry of Functional Groups, Suppl. C; Patai, S.; Rappoport, Z., Eds.; Wiley: New York, 1983, pt 1, pp 529 - 534.

(22) Fedenok, L.G.; Berdnikov, V.M.; Shvartsberg, M.S. J. Org. Chem. USSR 1973, 9, 1806 1809.

(23) Back, S.; Lutz, M.; Spek, A.L.; Lang, H.; van Koten, G J. Organomet. Chem. 2001, $620,227-234$.

(24) Thomas, R.; Mallajyosula, S.S.; Lakshmi, L.; Pati, S.K.; Kulkarni, G.U. J. Mol. Struct. 2009, 922, 46 - 50 . 
(25) Schindler, D.; Eißmann, F.; Weber, E. Org. Biomol. Chem. 2009, 7, 3549 - 3560.

(26) Desiraju, G.R. Angew. Chem. Int. Ed. 1995, 34, 2311 - 2327.

(27) Kitaigorodsky, A.I. Molecular Crystals and Molecules; Academic Press: New York, 1973.

(28) Kitaigorodsky, A.I. Organic Chemical Crystallography; Consultant Bureau: New York, 1961.

(29) Csöregh, I.; Czugler, M.; Ertan, A.; Weber, E.; Ahrendt, J. J. Incl. Phenom. 1990, 8, 275 $-287$.

(30) Ruffani, A.; Seichter, W.; Weber, E. J. Incl. Phenom. Macrocyl. Chem. 2010 (DOI 10.1007/s10847-010-9850-0).

(31) Desiraju, G.R.; Steiner, T. The Weak Hydrogen Bond; IUCr Monographs on Crystallography, Vol. 9; Oxford University Press: New York, 1999, pp 29 - 121.

(32) Rissanen, K. CrystEngComm 2008, 10, 1107 - 1113.

(33) Metrangolo, P.; Meyer, M.; Pilati, T.; Resnati, G.; Terraneo, G. Angew. Chem. Int. Ed. 2008, $120,6206-6220$.

(34) Ramasubbu, N.; Parthasarathy, R.; Murray-Rust, P. J. Am. Chem. Soc. 1986, 108, 4308 4314.

(35) Dance, I. In Encyclopedia of Supramolecular Chemistry; Atwood, J.L.; Steed, W.J., Eds.; CRC Press: Boca Raton, FL, 2004, pp 1076 - 1092.

(36) Hausdorf, S.; Seichter, W.; Weber, E.; Mertens, F.O.R.L., Dalton Trans. 2009, 1107 1113. 
(37) Böhle, T.; Schindler, D.; Hauptvogel, I.M.; Mertens, F.O.R.L.; Weber, E.; paper in preparation .

(38) Bonifazi, D.; Mohnani, S.; Llanes-Pallas, A. Chem. Eur. J. 2009, 15, 7004 - 7025.

(39) Payer, D.; Comisso, A.; Dmitriev, A.; Strunskus, T.; Lin, N.; Wöll, C.; De Vita, A.; Barth, J.V.; Kern, K. Chem. Eur. J. 2007, 13, 3900 - 3906.

(40) Kampschulte, L.; Lackinger, M.; Maier, A.-K.; Kishore, R.S.K.; Griessl, S.; Schmittel, M.; Heckl, W.M. J. Phys. Chem. 2006, B110, 10829 - 10836.

(41) Schütte, M.; Stolle, C.; Kurth, D.G. Supramol. Chem. 2003, 15, 549 - 555.

(42) Leonard, L.; Lugo, B.; Procter, G. Praxis der Organischen Chemie; VCH: Weinheim, Germany, 1994, pp 53 - 68.

(43) Sheldrick, G.M. Acta Crystallogr. 2008, A64, 112 - 122. 


\section{Captions to Figures}

Scheme 1. Chemical formulas of the compounds studied.

Scheme 2. Synthetic pathway for preparation of compound $\mathbf{1}$.

Figure 1. Perspective view of the asymmetric unit of $\mathbf{1 a}\left(\mathbf{1} \cdot 2 \mathrm{DMSO} \cdot \mathrm{CHCl}_{3}\right)$. Thermal ellipsoids are drawn at 50\% probability level. Broken lines represent hydrogen bonds.

Figure 2. Packing excerpt of 1a showing the mode of intermolecular interactions. Chlorine atoms are displayed as cross-hatched circles, oxygen atoms as dotted and sulfur atoms as shaded circles. Broken lines represent hydrogen bond type interactions.

Figure 3. Illustration of the plain lattice of 1 (excluding solvent molecules) viewed along the crystallographic $a$-axis. Oxygen atoms are displayed as shaded circles. Only the hydrogens of the carboxy groups are displayed for clarity. 
Table 1. Crystallographic and structure refinement data of the compound studied (estimated standard deviations are in parentheses).

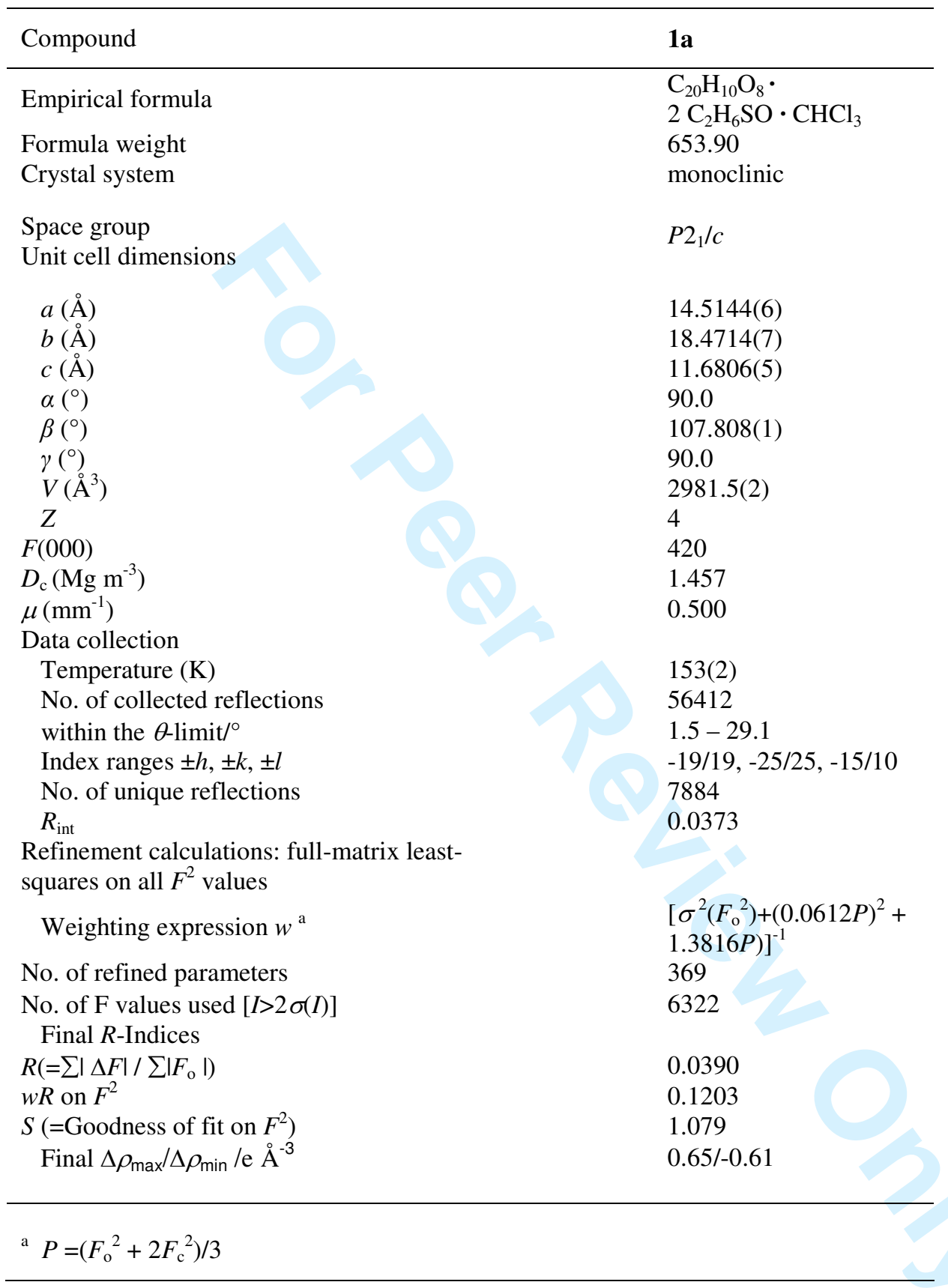


Table 2. Distances $(\AA)$ and angles $\left({ }^{\circ}\right)$ of possible hydrogen-bond type interactions of the compound studied.

\begin{tabular}{|c|c|c|c|c|}
\hline \multirow[t]{2}{*}{ Atoms involved } & \multirow[t]{2}{*}{ Symmetry } & \multicolumn{2}{|l|}{ Distance } & \multirow{2}{*}{$\begin{array}{l}\text { Angle } \\
\text { D-H } \cdots A\end{array}$} \\
\hline & & $\mathrm{D} \cdots \mathrm{A}$ & $\mathrm{H} \cdots \mathrm{A}$ & \\
\hline \multicolumn{5}{|l|}{1} \\
\hline $\mathrm{O}(2)-\mathrm{H}(2) \cdots \mathrm{O}(1 \mathrm{~B})$ & $-1+x, 1.5-y,-1.5+z$ & $2.637(2)$ & 1.82 & 163 \\
\hline $\mathrm{O}(4)-\mathrm{H}(4) \cdots \mathrm{O}(1 \mathrm{~B})$ & $1-x, 1-y, 1-z$ & $2.606(2)$ & 1.77 & 174 \\
\hline $\mathrm{C}(2 \mathrm{C})-\mathrm{H}(2 \mathrm{C} 1) \cdots \mathrm{O}(1 \mathrm{~B})$ & $x, y, z$ & $3.313(3)$ & 2.56 & 134 \\
\hline $\mathrm{O}(6)-\mathrm{H}(6) \cdots \mathrm{O}(1 \mathrm{C})$ & $x, y, z$ & $2.598(2)$ & 1.78 & 163 \\
\hline $\mathrm{O}(8)-\mathrm{H}(8) \cdots \mathrm{O}(1 \mathrm{C})$ & $1-x, 0.5+y, 1.5-z$ & $2.651(2)$ & 1.81 & 176 \\
\hline $\mathrm{C}(2 \mathrm{C})-\mathrm{H}(2 \mathrm{C} 2) \cdots \mathrm{O}(3)$ & $1-x, 0.5+y, 1.5-z$ & $3.310(3)$ & 2.43 & 149 \\
\hline $\mathrm{C}(2 \mathrm{~B})-\mathrm{H}(2 \mathrm{~B} 2) \cdots \mathrm{O}(4)$ & $1-x, 0.5+y, 0.5-z$ & $3.535(3)$ & 2.72 & 141 \\
\hline $\mathrm{C}(1 \mathrm{~A})-\mathrm{H}(1 \mathrm{~A}) \cdots \mathrm{O}(5)$ & $x, y, z$ & $3.093(3)$ & 2.20 & 155 \\
\hline $\mathrm{C}(1 \mathrm{~B})-\mathrm{H}(1 \mathrm{~B} 2) \cdots \mathrm{O}(7)$ & $1-x, 2-y, 1-z$ & 3.143(3) & 2.48 & 125 \\
\hline
\end{tabular}


Table 1. Crystallographic and structure refinement data of the compound studied (estimated standard deviations are in parentheses).

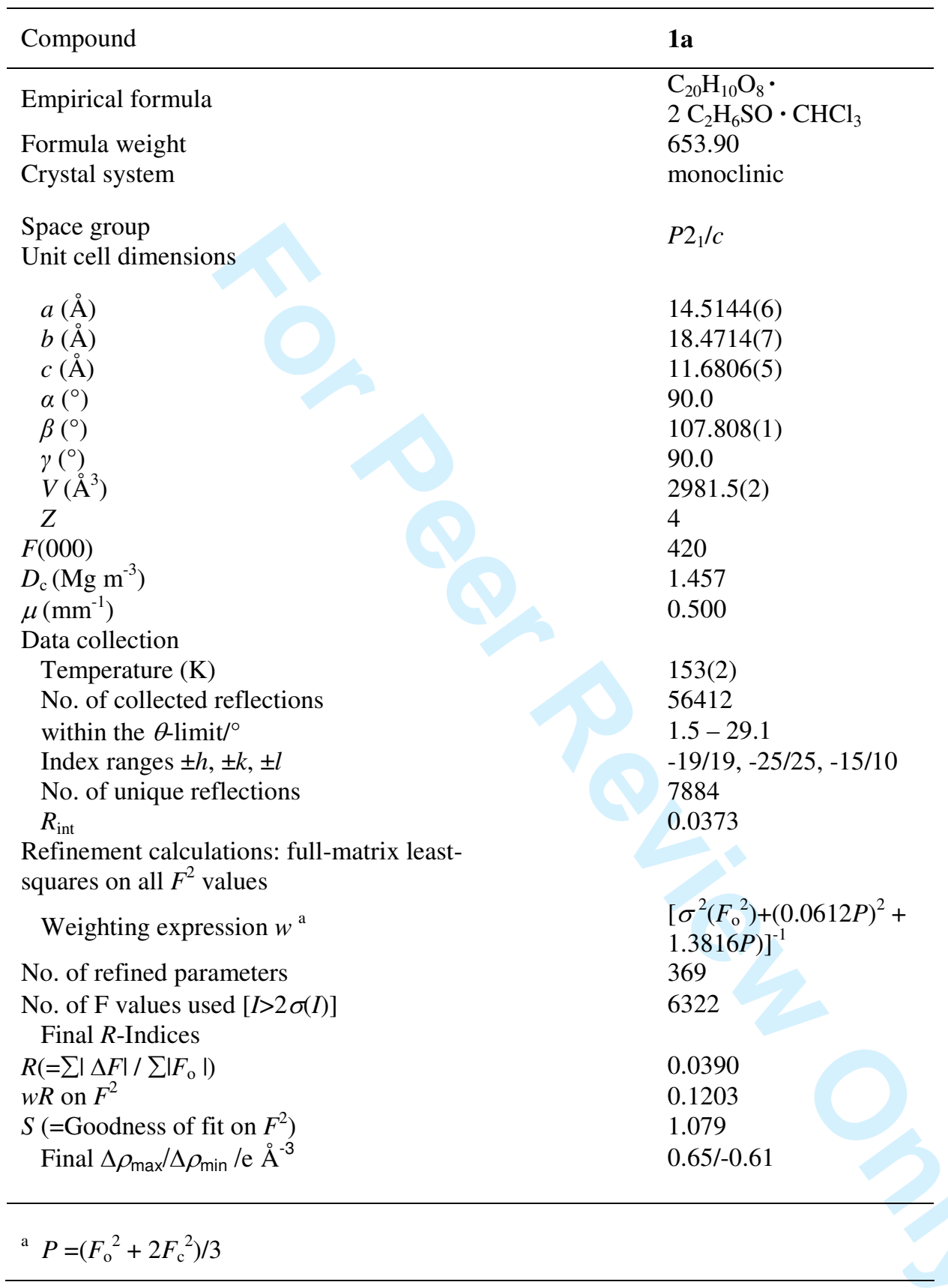


Table 2. Distances $(\AA)$ and angles $\left({ }^{\circ}\right)$ of possible hydrogen-bond type interactions of the compound studied.

\begin{tabular}{lllll}
\hline \multirow{2}{*}{ Atoms involved } & Symmetry & \multicolumn{2}{l}{ Distance } & \multirow{2}{*}{ Angle } \\
\cline { 3 - 3 } & & $\mathrm{D} \cdots \mathrm{A}$ & $\mathrm{H} \cdots \mathrm{A}$ & $\mathrm{D}-\mathrm{H} \cdots \mathrm{A}$ \\
\hline & & & & \\
$\mathbf{1}$ & & & \\
$\mathrm{O}(2)-\mathrm{H}(2) \cdots \mathrm{O}(1 \mathrm{~B})$ & $-1+x, 1.5-y,-1.5+z$ & $2.637(2)$ & 1.82 & 163 \\
$\mathrm{O}(4)-\mathrm{H}(4) \cdots \mathrm{O}(1 \mathrm{~B})$ & $1-x, 1-y, 1-z$ & $2.606(2)$ & 1.77 & 174 \\
$\mathrm{C}(2 \mathrm{C})-\mathrm{H}(2 \mathrm{C} 1) \cdots \mathrm{O}(1 \mathrm{~B})$ & $x, y, z$ & $3.313(3)$ & 2.56 & 134 \\
$\mathrm{O}(6)-\mathrm{H}(6) \cdots \mathrm{O}(1 \mathrm{C})$ & $x, y, z$ & $2.598(2)$ & 1.78 & 163 \\
$\mathrm{O}(8)-\mathrm{H}(8) \cdots \mathrm{O}(1 \mathrm{C})$ & $1-x, 0.5+y, 1.5-z$ & $2.651(2)$ & 1.81 & 176 \\
$\mathrm{C}(2 \mathrm{C})-\mathrm{H}(2 \mathrm{C} 2) \cdots \mathrm{O}(3)$ & $1-x, 0.5+y, 1.5-z$ & $3.310(3)$ & 2.43 & 149 \\
$\mathrm{C}(2 \mathrm{~B})-\mathrm{H}(2 \mathrm{~B} 2) \cdots \mathrm{O}(4)$ & $1-x, 0.5+y, 0.5-z$ & $3.535(3)$ & 2.72 & 141 \\
$\mathrm{C}(1 \mathrm{~A})-\mathrm{H}(1 \mathrm{~A}) \cdots \mathrm{O}(5)$ & $x, y, z$ & $3.093(3)$ & 2.20 & 155 \\
$\mathrm{C}(1 \mathrm{~B})-\mathrm{H}(1 \mathrm{~B} 2) \cdots \mathrm{O}(7)$ & $1-x, 2-y, 1-z$ & $3.143(3)$ & 2.48 & 125 \\
& & & & \\
\hline
\end{tabular}


<smiles>O=C(O)c1cc(C#CC#Cc2cc(C(=O)O)cc(C(=O)O)c2)cc(C(=O)O)c1</smiles>

\section{1}

1a $1 \cdot 2 \mathrm{DMSO} \cdot \mathrm{CHCl}_{3}$

Scheme 1 
<smiles>COC(=O)c1cc(I)cc(C(=O)OC)c1</smiles>

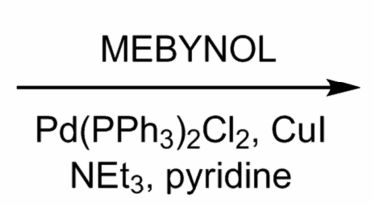<smiles>COC(=O)c1cc(C#CC(C)(C)O)cc(C(=O)OC)c1</smiles>

2

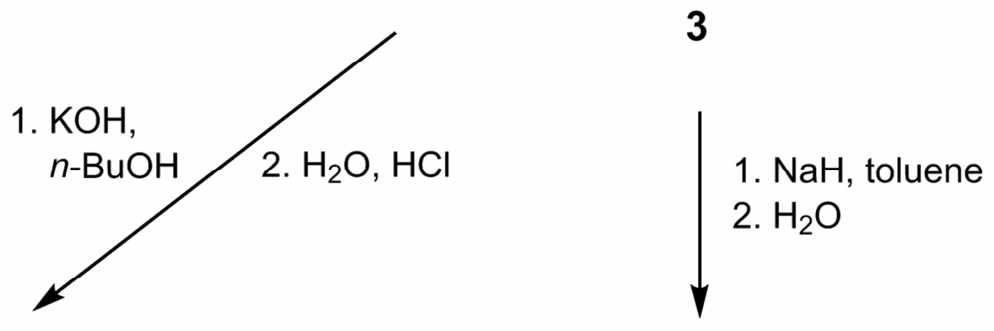<smiles>C#Cc1cc(C(=O)O)cc(C(=O)O)c1</smiles><smiles>C#Cc1cc(C(=O)OC)cc(C(=O)OC)c1</smiles>

4

5

1. $\mathrm{Cu}(\mathrm{OAc})_{2}$, pyridine $/ \mathrm{MeOH}$ 2. $\mathrm{H}_{2} \mathrm{SO}_{4}$<smiles>COC(=O)c1cc(C#CC#Cc2cc(C(=O)OC)cc(C(=O)OC)c2)cc(C(=O)OC)c1</smiles>

6

Scheme 2 


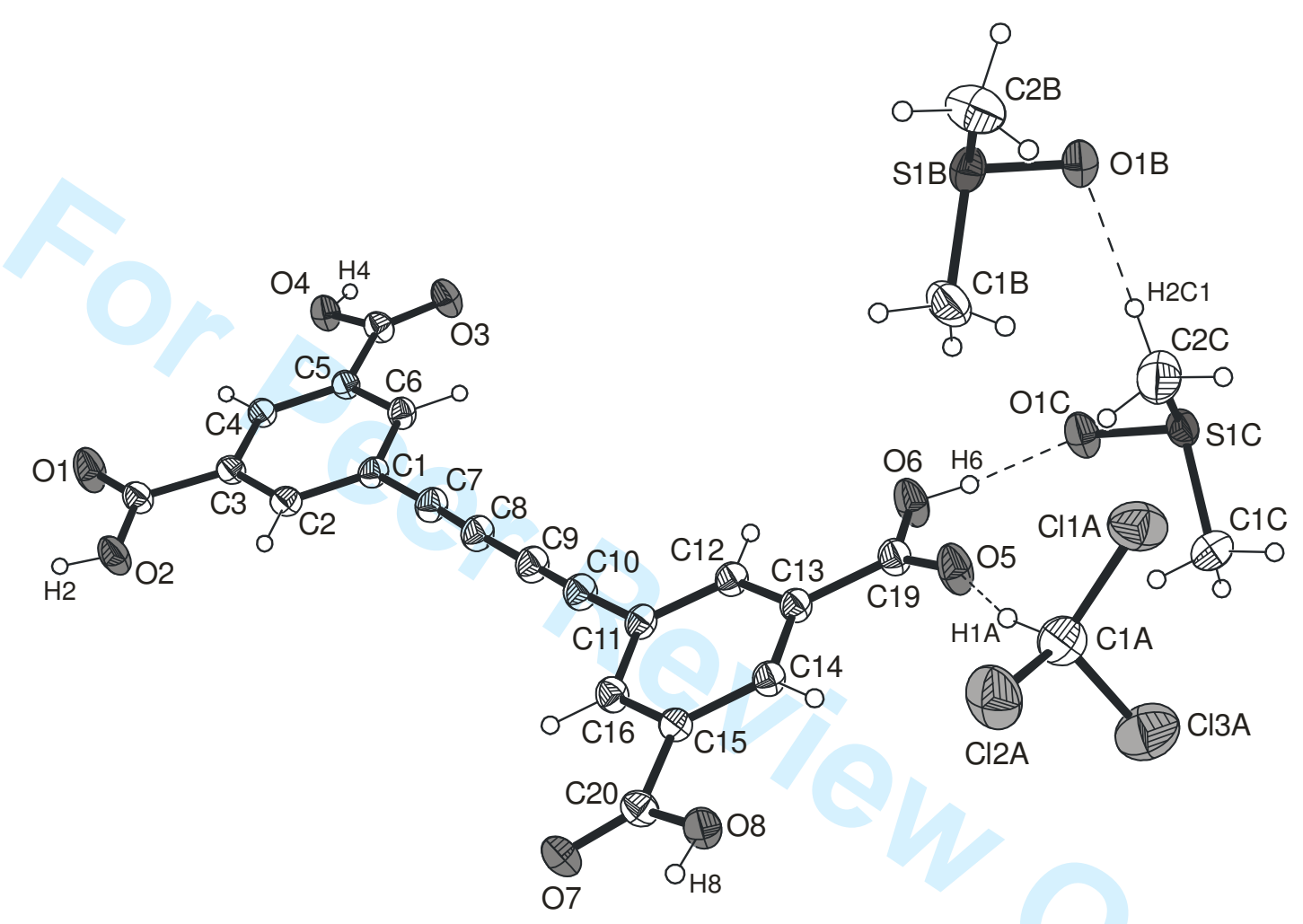

Fig. 1 


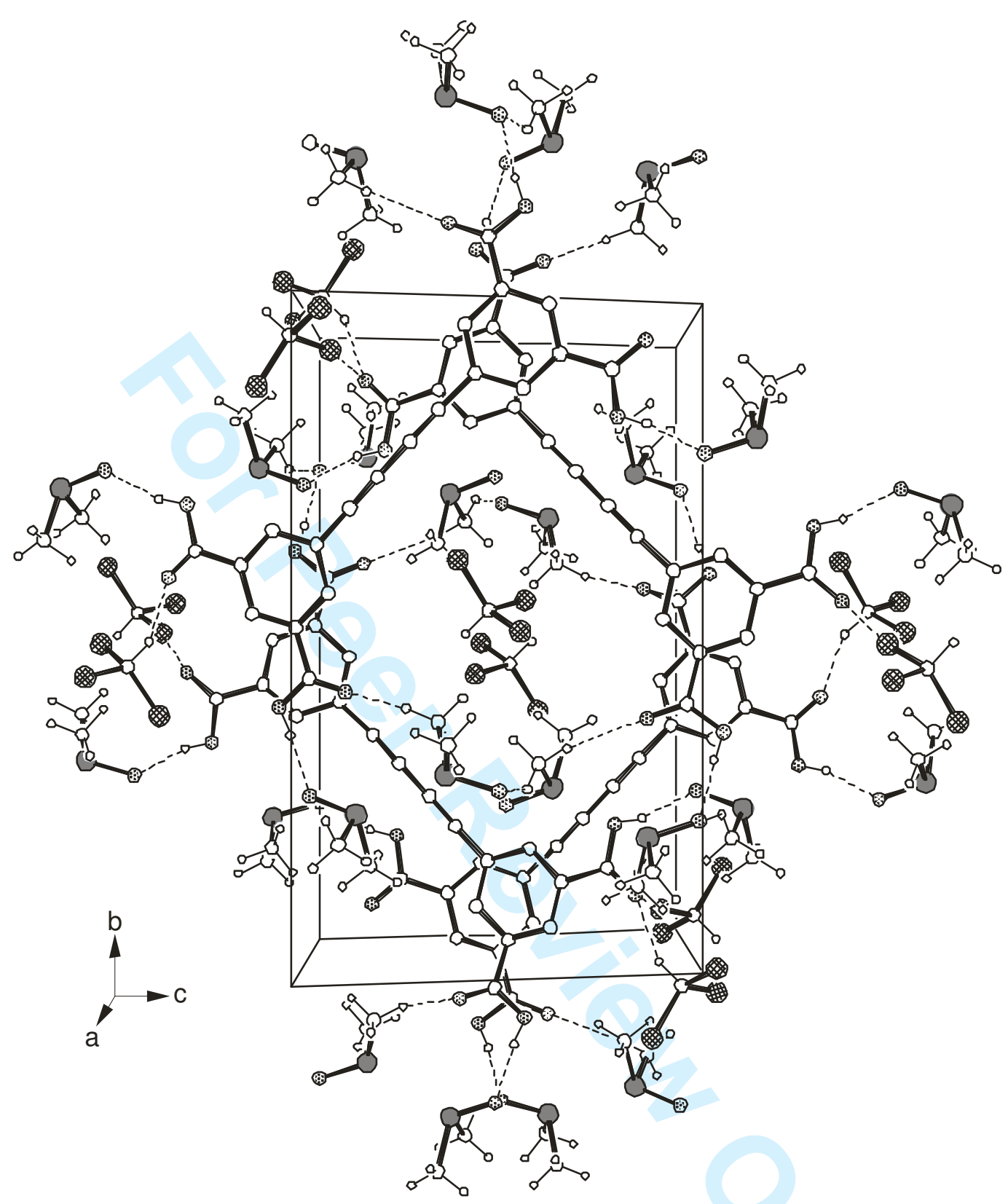

Fig. 2 


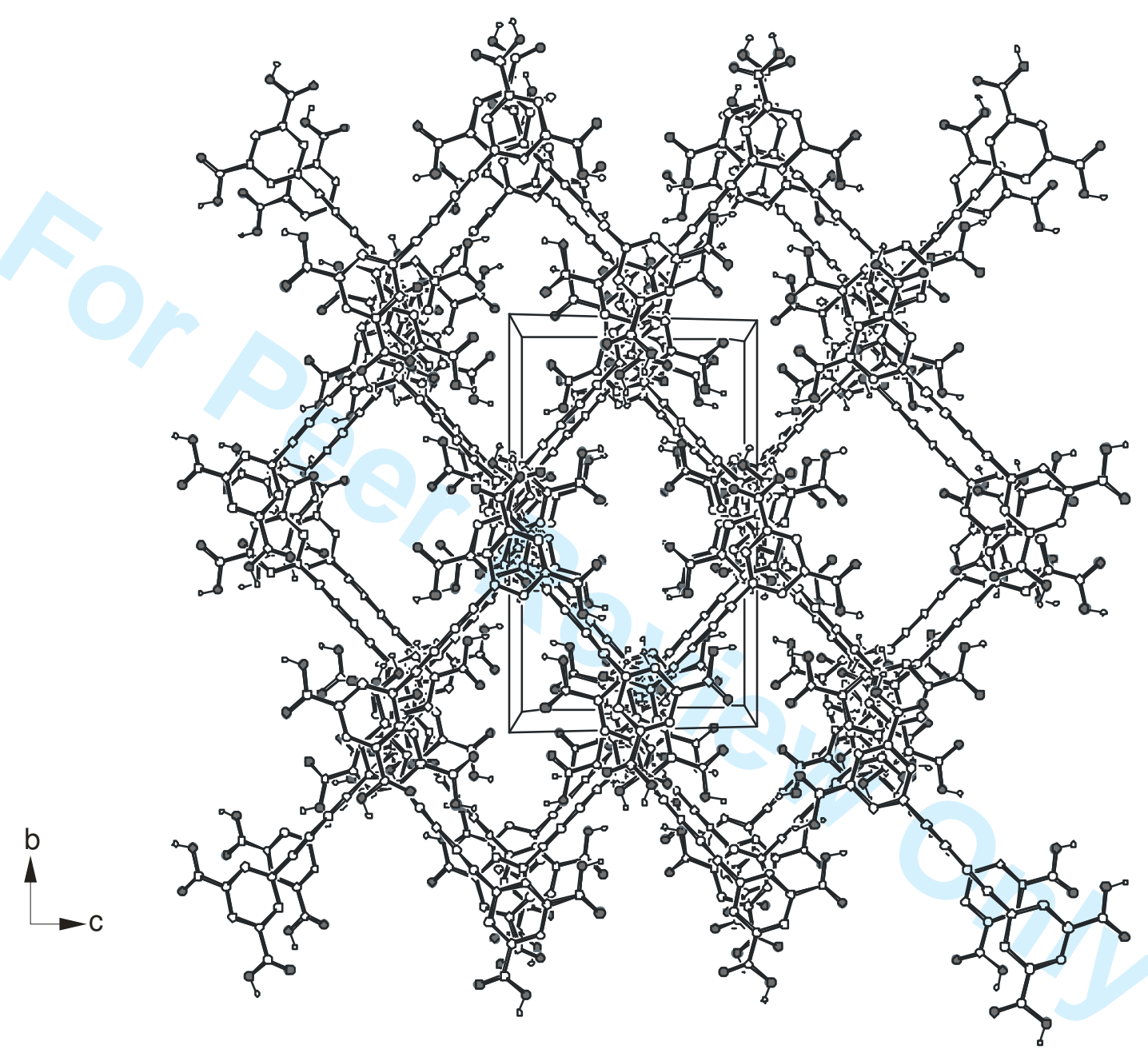

Fig. 3 